\title{
Next generation tissue engineering of orthopedic soft tissue-to-bone interfaces
}

\begin{abstract}
Alexander J. Boyst, Department of Materials Science and Engineering, Cornell University, Ithaca, New York, USA
Mary Clare McCorryt, Meinig School of Biomedical Engineering, Cornell University, Ithaca, New York, USA

Scott Rodeo, Orthopedic Surgery, Hospital for Special Surgery, New York, New York, USA; Sports Medicine and Shoulder Service, Hospital for Special Surgery, New York, New York, USA; Tissue Engineering, Regeneration, and Repair Program, Hospital for Special Surgery, New York, New York, USA; Orthopedic Surgery, Weill Medical College of Cornell University, Cornell University, New York, New York, USA; New York Giants, East Rutherford, New Jersey, USA; Department of Orthopedic Surgery, Hospital for Special Surgery, New York, New York, USA

Lawrence J. Bonassar, Meinig School of Biomedical Engineering, Cornell University, Ithaca, New York, USA; Sibley School of Mechanical and Aerospace Engineering, Cornell University, Ithaca, New York, USA

Lara A. Estroff, Department of Materials Science and Engineering, Cornell University, Ithaca, New York, USA; Kavli Institute at Cornell, Cornell University, Ithaca, New York, USA
\end{abstract}

Address all correspondence to Lawrence J. Bonassar at lb244@cornell.edu and Lara A. Estroff at lae37@cornell.edu

(Received 18 May 2017; accepted 28 August 2017)

\begin{abstract}
Soft tissue-to-bone interfaces are complex structures that consist of gradients of extracellular matrix materials, cell phenotypes, and biochemical signals. These interfaces, called entheses for ligaments, tendons, and the meniscus, are crucial to joint function, transferring mechanical loads and stabilizing orthopedic joints. When injuries occur to connected soft tissue, the enthesis must be re-established to restore function, but due to structural complexity, repair has proven challenging. Tissue engineering offers a promising solution for regenerating these tissues. This prospective review discusses methodologies for tissue engineering the enthesis, outlined in three key design inputs: materials processing methods, cellular contributions, and biochemical factors.
\end{abstract}

\section{Introduction}

Soft tissue-to-bone interfaces are present in many tissues, supporting movement in vertebrate animals. These interfaces mediate transitions between materials with highly dissimilar mechanical properties, with a three or more order of magnitude change in stiffness occurring over only a few hundred microns. ${ }^{[1-3]}$ While these interfaces are robust, undergoing wear and tear over the entire lifespan of humans, they fail in instances of extreme joint loading. Tissue engineered replacements can be constructed outside of the body and implanted as living tissue, offering a promising alternative to current repair options. This review discusses the structure and development of some representative orthopedic interfaces in the body (e.g., ligamentous, tendinous, and meniscal attachments) and how we can use this information to engineer living tissues for the repair and replacement of these mechanically, compositionally, and structurally complex interfaces.

The ligamentous, tendinous, and meniscal attachments, also called entheses, act to anchor soft tissues to bone. Injuries to the enthesis often result in acute disability and may ultimately predispose the affected joint to diseases such as osteoarthritis, a disease estimated to affect over $70 \%$ of people aged $55-78 .{ }^{[4]}$

$\dagger$ Authors contributed equally to the manuscript.
Severe injuries of these tissues often require replacement, which is typically accomplished using cadaveric tissue (allograft) or tissue removed from the patient's own body (autograft) (Fig. 1). Allograft tissue can effectively replace the damaged tissue in its entirety. For example, in the case of meniscus replacement, an allograft tissue consists of the entire meniscus, including the entheses. ${ }^{[5]}$ Proper fixation of the implant at the entheses is a necessity for surgical success. ${ }^{[6]}$ Including the entheses also obviates the need to reconstruct this complex interface between soft tissue and bone. Despite the advantages of allografts, limitations related to cost, tissue sizing, availability, and potential for an adverse immune response still exist. Autograft tissue is also frequently used for ligament and tendon repair, where a portion of the patient's native tendon is used. However, autograft tissue replacement can require multiple surgical sites, and harvest of autografts from ligament sites is not feasible. Tissue engineered implants combine the advantages of both the allograft and autograft options in that they offer a customizable, living implant that can be produced without requiring a donor or donor site.

Tissue engineering interfaces requires an interdisciplinary effort among biomedical engineers, materials scientists, and orthopedic surgeons. These tissues are complex in nature, consisting of multi-scale arrangements of multiple tissue types. 

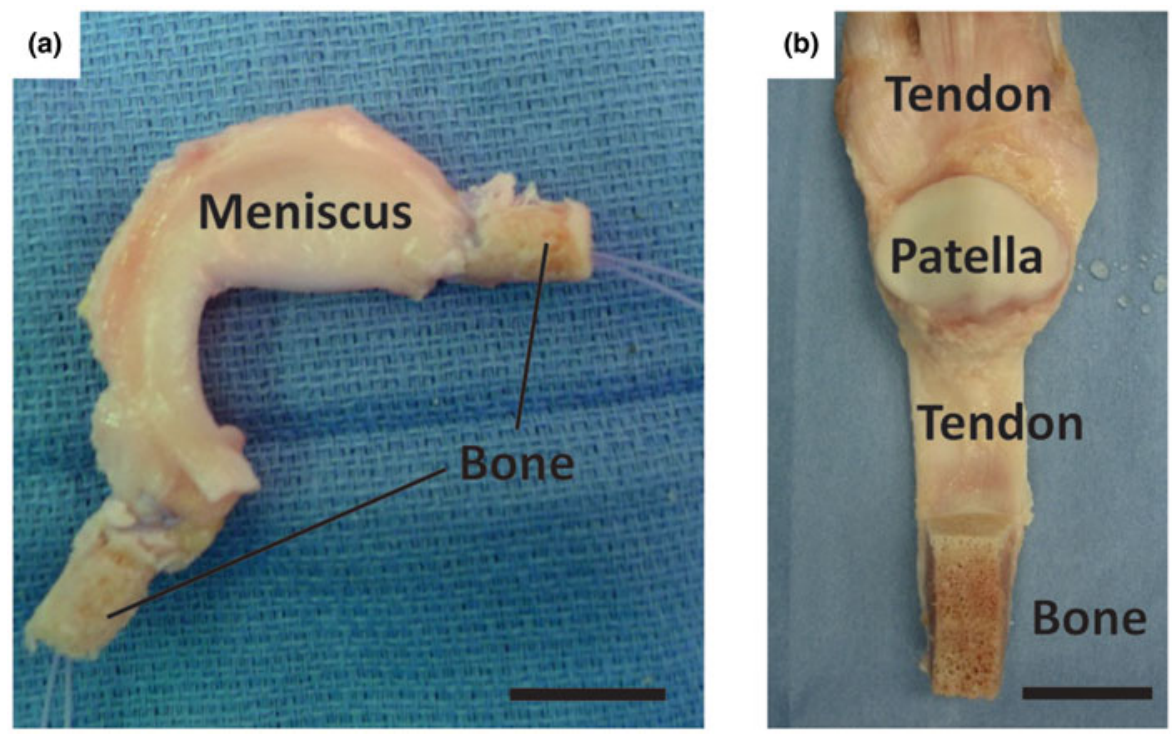

Figure 1. Surgical adult human allograft replacements for (a) meniscus and (b) patellar tendon with full bone insertions intact. Sutures are threaded through the insertion points and pulled into bone tunnels to anchor allograft tissues in place. Leaving the entheses intact obviates the need for enthesis healing, increasing the success rate for patient recovery. Scale bars are $20 \mathrm{~mm}$.

The mechanical function of these interfaces is derived in part from the hierarchical arrangement of relatively simple building blocks into composite materials. Interfacial tissues are integrated into a continuous gradient populated by a variety of cell types, and these cell types are accompanied by chemical factors and signaling molecules that influence the maturation of these tissues and maintain homeostasis. ${ }^{[7-9]}$ Two types of entheses can be found in the body: direct and indirect. Direct entheses have a fibrocartilaginous region between the bone and the highly organized collagen fibers of the ligament, tendon, etc. ${ }^{[10]}$ Conversely, indirect entheses are usually observed on the shafts of long bones and have fibers that connect directly into bone (Sharpey's fibers) (Fig. 2). This review will focus on direct entheses.

All direct entheses have the same general subdivisions based on tissue type, as observed through histological analysis: subchondral bone, calcified fibrocartilage, uncalcified fibrocartilage, and oriented soft tissue. ${ }^{[12-14]}$ Comparative structures of tendon, ligament, and meniscal entheses are highlighted using a tetrachrome stain of sagittal sections of these interfaces (Fig. 3). The extracellular matrix (ECM) of these tissues consists primarily of collagen, proteoglycans, and apatite. The interfacial region consists of a spatial distribution of cell types, moving from bone cells (osteoblasts, osteoclasts, osteocytes) to hypertrophic fibrochondrocytes in the calcified fibrocartilage to fibrochondrocytes in the uncalcified fibrocartilage to fibroblasts in the oriented collagenous region of the enthesis (Fig. 4). These cell types are accompanied by biochemical and biomechanical cues that also vary by region, often with temporal and spatial gradients in concentration. ${ }^{[15-18]}$ The demarcation between calcified and uncalcified fibrocartilage is called the tidemark, referring to a distinctive transition between tissue regions. However, recent evidence indicates the presence of a mineral gradient at what has been historically referred to as the tidemark, meaning that this shift in composition may be less distinct. ${ }^{[7,12,19]}$

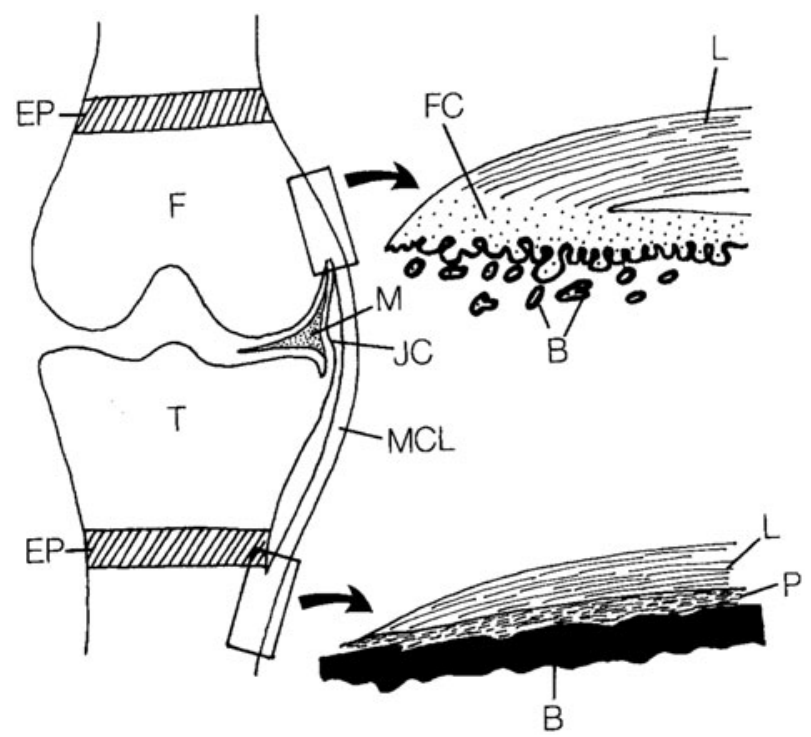

Figure 2. Schematic of the direct and indirect entheses for the femoral and tibial insertions of the medial collateral ligament (MCL), respectively. Abbreviations are as follows: femur $(F)$, tibia $(T)$, fibrocartilage $(F C)$, ligament $(\mathrm{L})$, bone $(\mathrm{B})$, periosteum $(\mathrm{P})$, meniscus $(\mathrm{M})$, joint capsule $(\mathrm{JC})$, and epiphyseal plate (EP). Reprinted from Springer Anatomy and Embryology, An immunohistochemical study of enthesis development in the medial collateral ligament of the rat knee joint, Volume 194, Issue 4, 1996, 399-406, J. Gao, K. Messner, J. R. Ralphs, M. Benjamin, (c) Springer-Verlag 1996, with permission of Springer. ${ }^{[11]}$ 


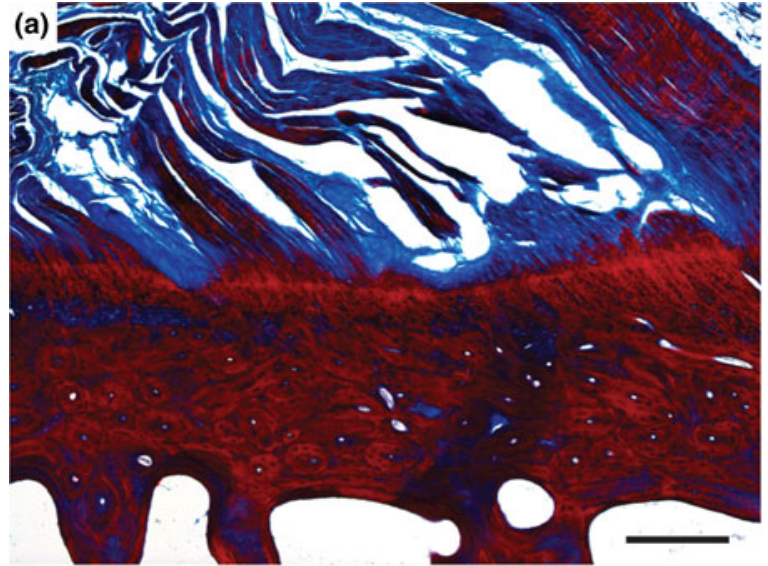

Femoral ACL insertion

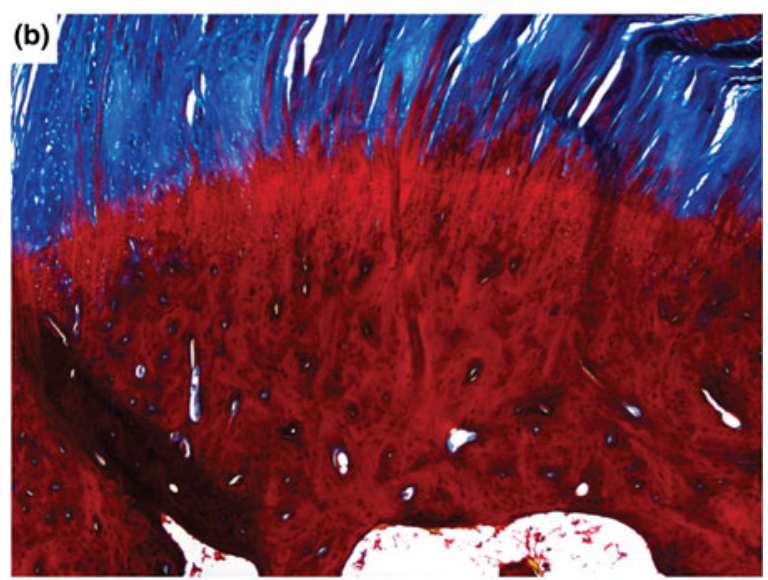

Achilles insertion

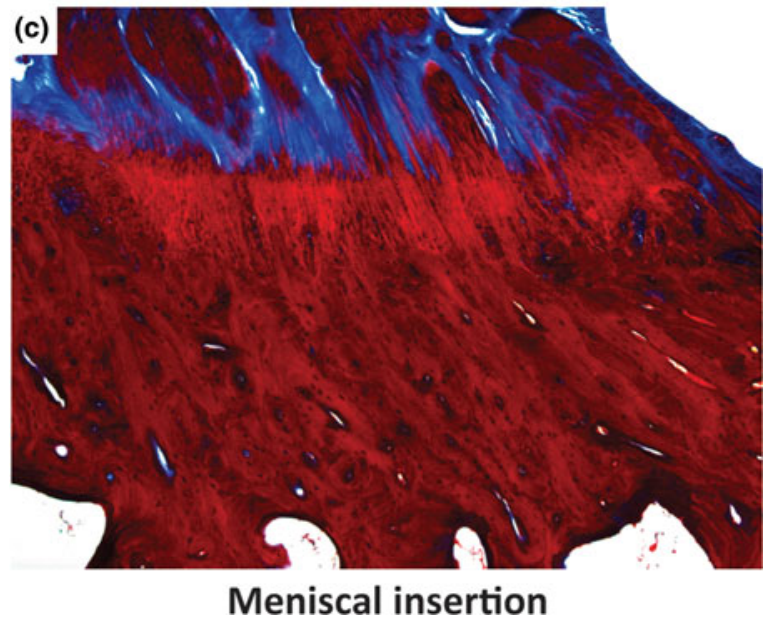

Figure 3. Light microscope images of three different osteochondral interfacial tissues, stained with tetrachrome stain. All images show ovine tissue, cut in the sagittal plane of the enthesis: (a) the femoral anterior cruciate ligament (ACL) insertion, (b) insertion point of gastrocnemius tendon with the calcaneal bone, referred to here as the Achilles insertion, and (c) the meniscal insertion. Trabecular pores are visible on the bottoms of each image, beneath dense calcified bone (deep red). Porous regions transition through to fibers (blue). Note the varying thicknesses of the interfacial regions, and variable morphology of the intermediate bony regions per anatomy. Scale bar is $400 \mu \mathrm{m}$.
As a prospective review, this paper highlights current methods of designing and fabricating a tissue engineered enthesis construct with a view toward future directions. Enthesis engineering is still at an early stage, even when compared with other tissue engineering efforts. While prior studies have examined methods to engineer bulk tendon, ligament, meniscus, and even other orthopedic interfaces, ${ }^{[20,21]}$ such as the osteochondral interface and the periodontal interface, ${ }^{[22,23]}$ few studies have focused on engineering entheseal tissues. ${ }^{[7-9]}$ This review divides the orthopedic interface engineering process into three main design inputs: materials processing methods, cellular contributions, and biochemical factors. These inputs must be developed in parallel for both the osteogenic and soft tissuegenerating portions of a construct, and then combined across an interfacial region of the construct to promote continuity and integration. This interface can be formulated into either continuous but opposing gradients of soft tissue and bone inputs or a compartmentalized interface, consisting of multiple regions that reflect the composition of the native tissue. Following tissue assembly, the maturation process is the key to promote eventual integration with the local joint tissues (Fig. 5). The following sections discuss these inputs individually and address how these methods can be utilized in parallel to generate soft tissue-to-bone interfaces.

\section{Materials processing methods}

The architecture of the enthesis is complex, consisting of hierarchical arrangements of collagen fibrils, proteoglycans, and apatite $\left[\mathrm{Ca}_{10}\left(\mathrm{PO}_{4}\right)_{6}(\mathrm{OH})_{2}\right]$ crystals. The molecular composition, spatial distribution, and nano- to micro-scale assembly of these components dictate the properties of each tissue region and are critical for defining the mechanical stability of the entire enthesis. The following sections describe the native enthesis structure and methods for mimicking this structure through tissue engineering.

\section{Native organization}

Collagen is the main component of the enthesis. Three major types of collagen are found across the interface: type I, type II, and type X. Collagens III, V, and VI are also found in these interfaces at much lower concentrations. ${ }^{[24]}$ Types I and II collagen are fibrillar collagens, meaning they self-assemble into organized nanofibers, $\sim 50-500 \mathrm{~nm}$ in diameter. ${ }^{[25]}$ Type I collagen is deposited in association with tensile forces and is found in bone and ligamentous tissue. Type II collagen is associated with compressive forces and is found primarily in fibrocartilaginous regions. ${ }^{[15,26]}$ The presence of compressive forces has been postulated to aid in the reduction of stress concentrators in the enthesis, possibly indicating the origin of type II collagen. ${ }^{[27]}$ These fibrillar collagens can further assemble into increasingly large fiber-like structures. This type of organization is found within the oriented soft tissue of the entheseal attachments and is typically associated with type I collagen. Collagen fibrils in this region can bundle together into structures called fascicles, $\sim 50-300 \mu \mathrm{m}$ in diameter, which are in 

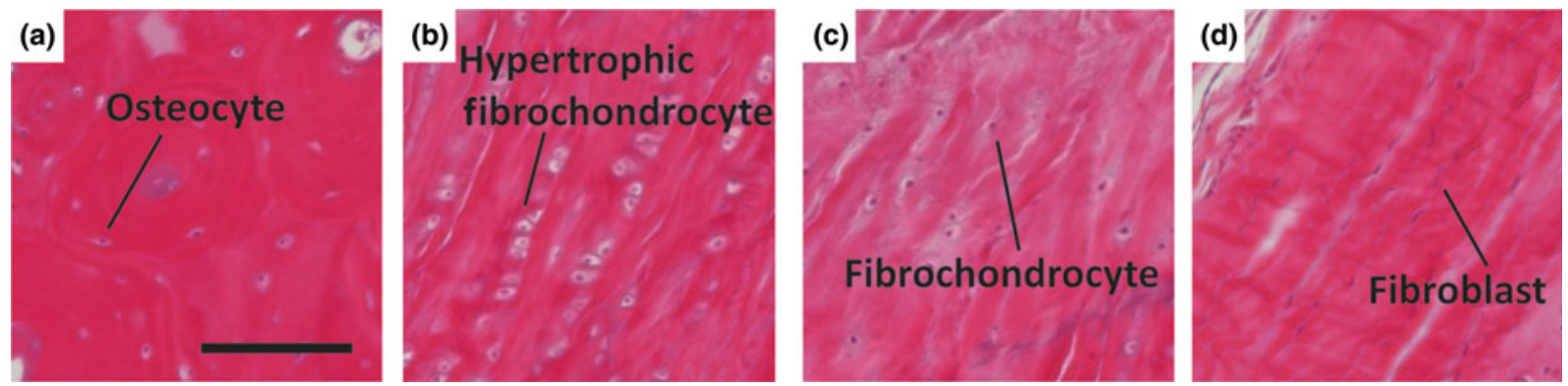

Figure 4. Representative histologic images of cellular phenotypes from (a) bone, (b) calcified fibrocartilage, (c) fibrocartilage, and (d) ligament from a mature ovine ACL enthesis (hematoxylin and eosin). (a) Osteocyte embedded between lamellae of an osteon. (b) Enlarged hypertrophic fibrochondrocytes organized in columns indicating rapid proliferation. (c) Fibrochondrocyte in disorganized fiber region. (d) Elongated spindle shaped fibroblast between large organized fibers. Scale bar is $200 \mu \mathrm{m}$.

turn bundled into large fibers, $\sim 100-500 \mu \mathrm{m}$ in diameter. ${ }^{[25]}$ Type $\mathrm{X}$ collagen is found in calcified fibrocartilage regions and is non-fibrillar. ${ }^{[15]}$ Type $\mathrm{X}$ collagen is thought to play a role in ossification, but its exact function is unknown. Hypotheses include type X collagen acting to regulate mineralization at the ossifying front, and type $\mathrm{X}$ collagen functioning as a matrix protein and facilitating the ingrowth and mineralization of new bone. ${ }^{[28]}$

The enthesis contains proteoglycans that bind water, provide compressive strength, and contribute to collagen fiber formation. Proteoglycans consist of a central core protein and at least one covalently attached glycosaminoglycan (GAG) chain. GAGs are linear, highly charged polysaccharides that can contain sulfate and carboxylate groups. ${ }^{[29]}$ Aggrecan is the predominant proteoglycan in cartilage and fibrocartilage and is the largest of the proteoglycans. In tendon and ligament, aggrecan is most prevalent in regions of compression and in the fibrocartilage of the insertion site. ${ }^{[24,30]}$ Similar to ligament and tendon, aggrecan in the meniscus is located in the inner portion of the meniscus, which is subject to more compressive loads, and the entheseal attachments. ${ }^{[31,32]}$ The large "bottle brush" structure and negative charge of aggrecan helps to bind and retain water, which contributes to the ability of the tissue to resist compression. ${ }^{[33]}$ Small leucine-rich proteoglycans (SLRPs) such as fibromodulin, decorin, and biglycan are known to bind to collagen and help to regulate collagen fiber formation and maintenance. ${ }^{[34-36]}$ SLRPs are prevalent in association with highly organized collagen bundles of tendon, ligament, and meniscus. ${ }^{[32,37]}$ Aggrecan is often found in regions of soft tissue-to-bone interfaces under compressive loading, while SLRPs are found in regions with large fibers experiencing tensile loads. ${ }^{[32]}$

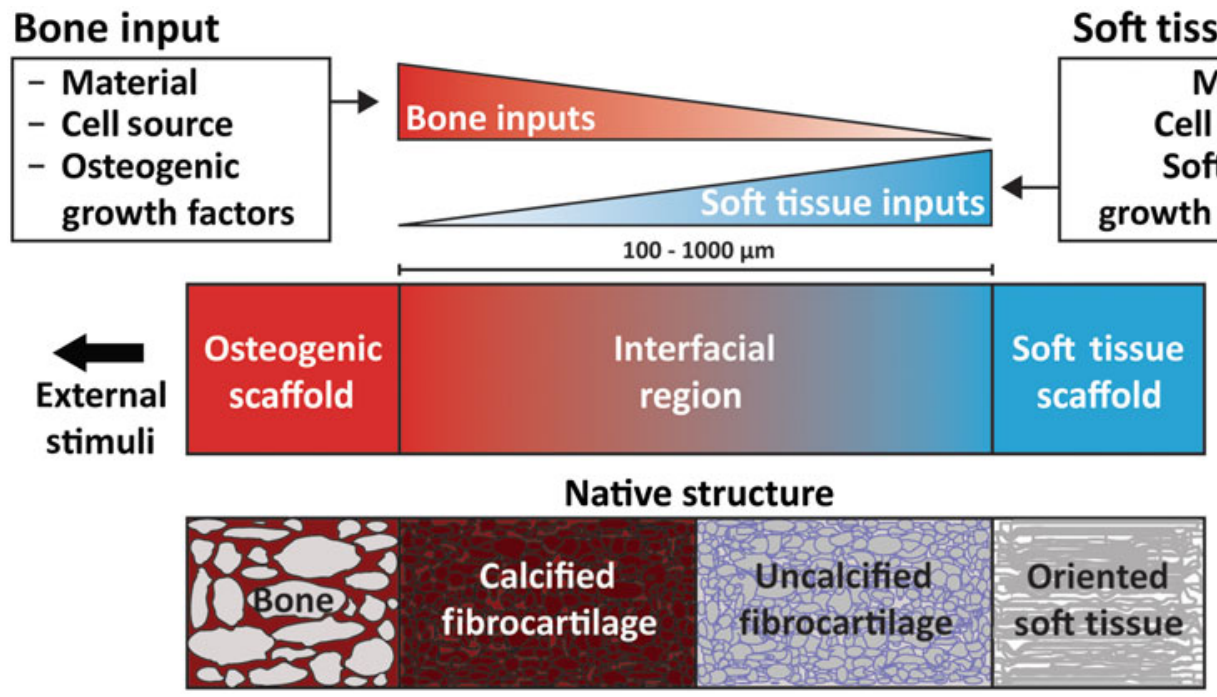

Figure 5. Schematic highlighting the process for constructing a tissue engineered interfacial construct. Materials, cell source, and growth factors are the central input considerations for a tissue engineering study design. The interfacial region requires complementary gradients of bone and soft tissue inputs. Following construct assembly, external stimuli such as mechanical loading can be applied to further aid in tissue development. 
Apatitic mineral is found within the subchondral bone and calcified fibrocartilage regions of the interfacial tissues. The mineral phase is primarily non-stoichiometric hydroxyapatite with carbonate substitutions, as opposed to geologic hydroxyapatite, ${ }^{[38]}$ that is arranged into nanocrystalline platelets. In bone, these platelets are contained within collagen fibrils and are oriented with their $c$-axis parallel to the direction of the fibril. Non-collagenous proteins are thought to organize the apatite platelets into the intrafibrillar spacing of collagen, but the exact mechanism through which this hierarchical structuring occurs is unknown. ${ }^{[39]}$ Thorough reviews of bone structure are available. ${ }^{[40,41]}$ The mineral phase in calcified fibrocartilage is also mainly carbonate-substituted hydroxyapatite, but the organization of the crystals within the matrix is not as well understood. $^{[12,42]}$

Aggregating the above information, subchondral bone consists of type I collagen fibrils infiltrated with nanocrystalline, carbonated apatite arranged circumferentially around pores, typically of the order of $1 \mathrm{~mm}$ in diameter. ${ }^{[43]}$ This structure transitions into non-porous calcified fibrocartilage, consisting of type II and type X collagen, apatitic mineral, and proteoglycans. Uncalcified fibrocartilage consists of splayed fibrils of type II collagen with proteoglycans. These splayed fibrils transition from the uncalcified fibrocartilage region into large type I collagen fibers that make up the oriented fiber region of the enthesis. ${ }^{[32,44]}$ Understanding native structure/composition should inform material selection for tissue engineering.

\section{Materials selection}

Appropriate materials for a tissue engineered scaffold must possess adequate mechanical properties, support cellular attachment and differentiation/proliferation, and potentiate cellular remodeling. Since the modulus ranges drastically across soft tissue-to-bone interfaces, a variety of materials have been used for tissue engineered constructs. To match the moduli of the stiff, mineralized regions of the enthesis, various calcium phosphate minerals, such as hydroxyapatite and tricalcium phosphate, and bioglass have been used. ${ }^{[45-51]}$ The compliant portions of the enthesis have been constructed from polymers and copolymers consisting of poly(capralactone) (PCL), poly (lactic acid) (PLA), poly(glycolic acid) (PGA), and/or poly(ethylene glycol) diacrylate, ${ }^{[49,51-56]}$ as well as other biopolymers such as silk, agarose, gelatin, hyaluronic acid, and collagen. ${ }^{[48,57-62]}$ Decellularized or demineralized native matrices have also been used to engineer the enthesis. ${ }^{[49,60,61,63,64]}$

\section{Materials-based design and fabrication}

The complex structure of the enthesis is related to its function, providing continuity and integration between multiple tissues with differing properties. The necessity for this integration and continuity arises from the loading of such interfaces in tension; ${ }^{[8]}$ hence, failure modes like delamination become relevant for poorly integrated constructs. To promote continuity, various materials processing techniques have been used. Many of these techniques revolve around the construction of gradients or the binding of multiple "compartmentalized" materials. Controlled crystal growth on electrospun poly(lactic-co-glycolic) acid (PLGA) resulted in a nanofiber scaffold with a mineral gradient. ${ }^{[4]}$ This gradient was formed through syringe pump-mediated injection of a calcium and phosphate salt-containing solution. Upon cell seeding, the activity of alkaline phosphatase (ALP), an enzyme associated with mineral deposition, the expression of RUNX2, an osteoblast-related transcription factor, and the expression of osteocalcin, an osteoblast-related protein, were correlated with mineral deposition. Cellular density and cell proliferation were negatively correlated with mineral deposition. ${ }^{[47]}$ These results indicate that proper processing and appropriate arrangement of enthesis-related materials result in spatially localized cellular responses that mimic those found in the body. However, implantation of this scaffold for the repair of the murine supraspinatus tendon resulted in scar formation, indicating that further processing is required for optimal enthesis reconstruction. ${ }^{[65]}$

Regional integration in scaffolds can also be induced through the production of microstructure gradients. For example, freezecasting coupled with salt-leaching enabled the formation of a multi-region scaffold composed of silk fibroin [Fig. 6(a)]. ${ }^{[58]}$ The processing conditions were designed to form a continuous scaffold with a porous, trabecular bone-like structure that transitions into a fiber-like morphology. The porous region results from salt leaching, in which a solution of silk fibroin and $\mathrm{NaCl}$ is frozen and freeze-dried. The precipitated salt crystals are subsequently dissolved, creating pores within the silk matrix. This region transitions to a fiber-like morphology, created using freeze casting, a process in which directional freezing is used to grow elongated ice crystals within a polymer solution. During solidification, the polymer, i.e., silk fibroin, is concentrated into the boundaries between the crystals. ${ }^{[66]}$ Upon sublimation of the ice crystals, oriented fiber-like structures composed of silk fibroin remain. These processing methods result in a continuous silk structure that mimics the morphology of collagen in the native enthesis. ${ }^{[58]}$ Similar scaffolds have been produced for the osteochondral interface, demonstrating the customizability of these techniques. ${ }^{[67]}$

Structural characteristics are important in that they not only affect the mechanical properties of the scaffold but also drive cellular differentiation. Fiber alignment drives matrix deposition rates in meniscal fibrochondrocytes and mesenchymal stem cells (MSCs) (the progenitor cells for bone, cartilage, etc.). ${ }^{[70]}$ Pore size affects the production of cartilage matrix proteins by cells. For example, smaller pore sizes cause cells to produce more GAGs. ${ }^{[22]}$ In addition to structurally derived cellular effects, the material composition of scaffolds also has an effect on differentiation. The addition of hydroxyapatite to scaffolds improves osteogenic properties and increases cellular attachment, ${ }^{[45,56]}$ and the presence of GAGs in scaffolds drives cells toward a chondrogenic lineage. ${ }^{[71,72]}$

The use of materials to control cellular responses can also be achieved through biodegradability and remodeling. For example, a compartmentalized triphasic scaffold, created by sintering polyglactin mesh, PLGA microspheres, and bioglass and 
(a)

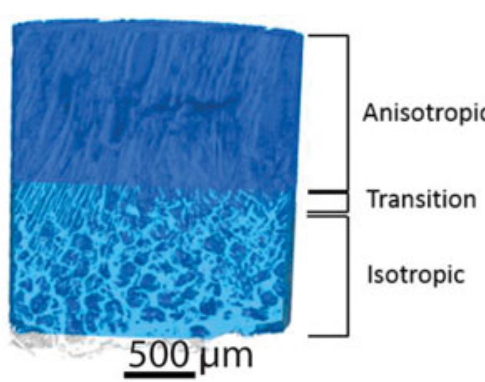

(b)

Materials processing methods
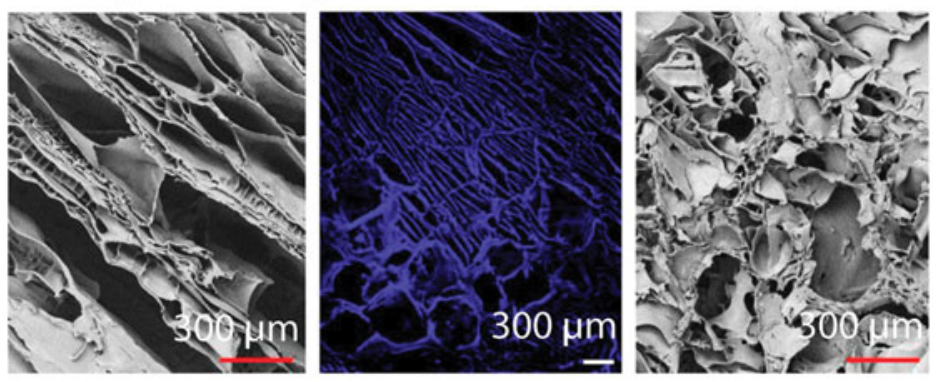

\section{Cellular considerations}
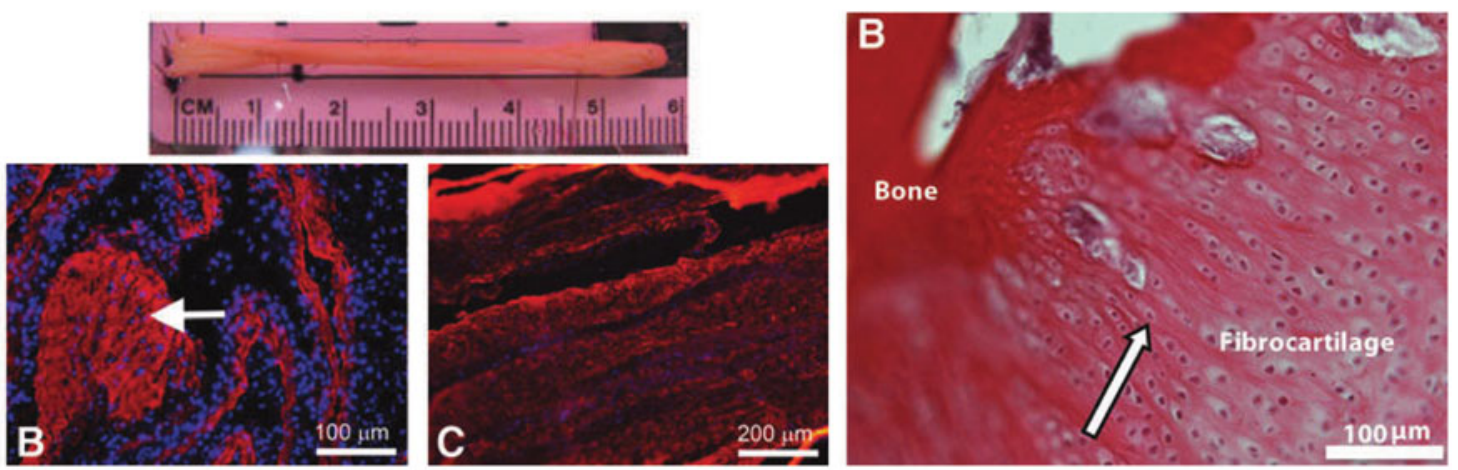

(c)

\section{Biochemical factors}
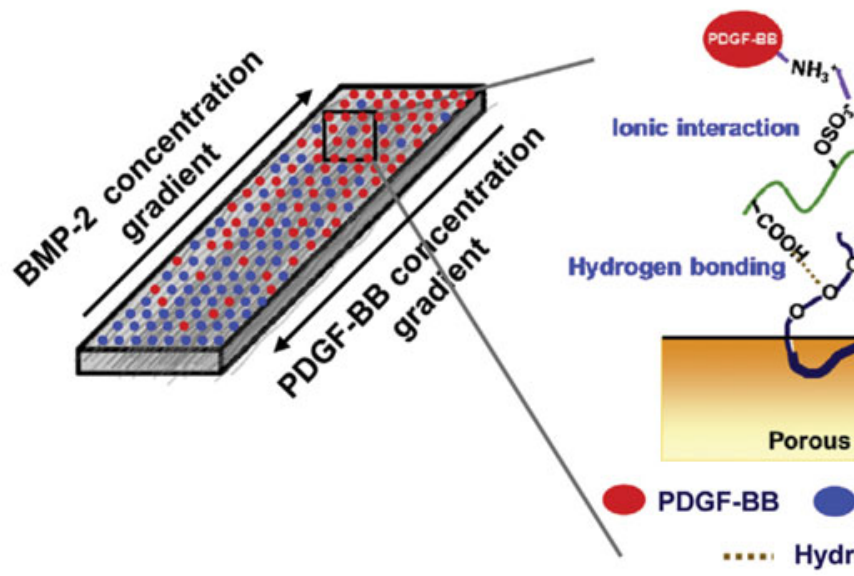

ic interaction
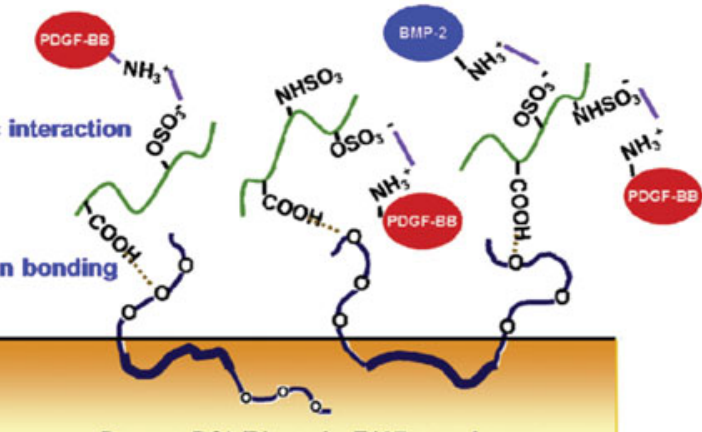

Porous PCL/Pluronic F127 membrane

PDGF-BB

BMP-2

? Pluronic F127

Ionic interaction

Figure 6. Examples of tissue engineered interface constructs for soft tissue to bone. (a) Biphasic anisotropic silk fibroin scaffold with integrated fiber/bone interface. Images from left-to-right: $\mu \mathrm{CT}$ of full construct, field emission scanning electron microscopy (FESEM) image of, anisotropic (fiber) region,

fluorescence microscopy image of transition region, and FESEM image of porous (trabecular) region. Reprinted with permission from TISSUE ENGINEERING, Part A, Volume 23, Issue 15-16, published by Mary Ann Liebert, Inc., New Rochelle, NY ${ }^{[58]}$ (b) Bone-ligament-bone ACL replacement generated using stem cell self-assembly and targeted differentiation. Images from left-to-right: full tissue engineered construct, immunostained for collagen (red) and DAPI-stained (nuclear stain) section showing bony region prior to implantation, immunostained for collagen (red) and DAPI-stained (nuclear stain) section showing ligament region prior to implantation, image of regenerated fibrocartilaginous region with aligned nuclei (arrow) after 2 months implantation. Reprinted with permission from TISSUE ENGINEERING, Part A, Volume 18, Issue 1-2, published by Mary Ann Liebert, Inc., New Rochelle, NY. ${ }^{[68]}$ (c) Porous membrane with inverse gradients of PDGF and BMP-2 for tendon-bone repair. Reprinted from Acta Biomaterialia, Volume 10, Issue 3, Hyun Ki Min, Se Heang Oh, Jonh Min Lee, Gun II Im, Jin Ho Lee, Porous membrane with reverse gradients of PDGF-BB and BMP-2 for tendon-to-bone repair: In vitro evaluation on adipose-derived stem cell differentiation, 1272-1279, Copyright (C) 2013, with permission from Elsevier ${ }^{[69]}$

PLGA microspheres together, shows varying rates and types of tissue ingrowth into the scaffold following subcutaneous implantation. ${ }^{[51]}$ All regions of the scaffold showed collagen deposition, and the bioglass and PLGA microsphere region allowed for mineral deposition. The polyglactin region degraded entirely, producing a fibrocartilage-like area between the polyglactin and PLGA microsphere region. ${ }^{[51,73]}$ In design of scaffolds that utilize multiple materials, structural 
considerations must be made for the types of mechanical forces to which the scaffold will be subjected. For example, fused microspheres are resistant to compression and polyglactin mesh is resistant to tension, but neither structure is designed to resist shear. Additionally, the differing structures could result in stress concentrations at the interface between the materials, arising from dissimilarities in their Poisson's ratios. Use of biodegradable materials can promote tissue infiltration, and particularly in this case, can be used to diminish the sharpness of the interface over time. The mechanism of biodegradation should also be considered for tissue engineering. Biodegradable polymers like PLA and PGA can be degraded through hydrolysis, opening up space for tissue to grow into, whereas biopolymers such as collagen must be enzymatically degraded and rearranged by cells, providing a template for remodeling. For example, cells rearranged collagen gels into large, oriented fibers during culture of a meniscus construct, indicating the value of incorporating cellular remodeling capability into a scaffold. ${ }^{[7]}$ Implementation of continuity, integration of structure, and support for cellular remodeling in scaffolds allow for control of mechanical properties, strengthening of interfacial regions, and ability of the scaffold to integrate with native tissue upon in vivo implantation.

\section{Cellular contributions}

Cells and cellular interactions drive the maturation of scaffolds before implantation and integration of scaffolds with native tissue after implantation; therefore, cellular content is an essential component to the design of any tissue engineered construct. Biocompatibility, cellular integration, and cellular remodeling are key considerations when creating, culturing, and implanting a construct. Cells function in complex three-dimensional (3D) environments and respond to a plethora of inputs including materials interactions, substrate stiffness, mechanical conditioning, biochemical signaling, and cell-cell interactions. Tissue engineering approaches utilize such inputs to drive maturation of a functional construct.

\section{Native cell types}

Soft tissue-to-bone interfaces span four regions with distinct cellular phenotypes (Figs. 3 and 4). Each cellular type found in the enthesis has a distinctive behavior, cell shape, matrix production profile, and genetic expression that define its phenotype. Osteoblasts, osteoclasts, and osteocytes are the three main cell types that reside in bone. Osteoblasts initiate new bone formation, while osteoclasts resorb and remodel bone. An osteocyte is a terminally differentiated osteoblast that resides in the mineralized matrix to maintain bone homeostasis [Fig. 4(a)]. Together, these cells regulate bone formation and maintenance. The bone phenotype is typically quantified by expression or accumulation of proteins, such as osteopontin and osteocalcin, type I collagen, markers of mineralization, such as ALP activity, and expression of transcription factors, such as RUNX2. ${ }^{[75]}$ The transition from bone to the calcified fibrocartilage region is regulated by hypertrophic fibrochondrocytes [Fig. 4(b)]. Hypertrophy is the process in which chondrocytes increase in size and secrete type X collagen in a mineralized cartilaginous matrix. ${ }^{[76]}$ In contrast, chondrocytes are found in cartilage and exhibit a rounded morphology. These cells reside in a proteoglycan-rich (mostly aggrecan) matrix composed of collagens I and II. Chondrocytes, found in the cartilaginous tissue, have upregulated levels of aggrecan, type II collagen, link protein, Sox9, and COMP genes. ${ }^{[77]}$ Fibrochondrocytes that reside in the uncalcified fibrocartilage region of the enthesis are named as such because they exhibit phenotypic markers of both fibroblasts and chondrocytes [Fig. 4(c)]. ${ }^{[78]}$ The native cell phenotypes serve as benchmarks for cell behavior and stem cell differentiation in tissue engineered constructs. Ligament cells and tenocytes (tendon cells) are often described as exhibiting a fibroblastic phenotype due to their spindle shape and production of type I collagen [Fig. 4(d)].$^{[18]}$ While these two cell types belong to distinctly different tissues, they share many common markers. Key positive markers for this phenotype are production of type I collagen, tenascin-C, scleraxis, tenomodulin, and proteoglycans such as decorin, biglycan, versican, lumican, and fibromodulin. ${ }^{[79,80]}$

\section{Tissue engineering with cells}

A consistent challenge of producing these soft tissue-to-bone interfaces is incorporating cells into the materials processing methods of the scaffold. Cellularizing these constructs can be accomplished by either encapsulating cells directly into the scaffold or by seeding cells onto the material surface and directing migrating cells into the scaffold. Growth factors or other chemoattractants are useful to encourage cellular migration and infiltration into scaffolds. ${ }^{[64,81,82]}$ Processing cells and materials together restricts the conditions in which a scaffold can be processed. Cells require a specific operational window of temperature, $\mathrm{pH}$, pressure, strain, osmolarity, and ion and solute balance in order to maintain viability. Furthermore, the soft tissue-to-bone interface contains an array of cell types. The number of cell types and the cellular locations in the tissue engineered scaffold play a role in soft tissue-to-bone interface assembly, culture, and development.

Given the gradient of cell types present in the enthesis, co-culture is one method to generate a graded interface. Different cell types are constantly interacting during native development and have intertwined signaling feedback mechanisms that are critical to development. ${ }^{[18,76,83]}$ Ex vivo co-culture mediates cell-cell contact and paracrine interactions that have been shown to influence cellular phenotype. Co-culturing of chondrocytes and osteoblasts in direct contact using a high cell density 3D micromass reduced GAG deposition in chondrocytes and cell-mediated mineralization in osteoblasts. ${ }^{[84]}$ Furthermore, co-culture can be used as a tactic to guide stem cell differentiation. ${ }^{[85-89]}$ One strategy to create an integrated gradient is to co-culture the desired cell types and generate cell gradients that utilize cell-cell interactions to mature the material into a graded interface. For ligament- 
bone interfaces, 2D co-culture of fibroblasts and osteoblasts, modeled using a fibroblast region, interface region, and osteoblast region, decreased cell proliferation and increased cellmediated mineralization by fibroblasts. In addition, production of type II collagen and aggrecan increased, indicating that co-culture interactions can lead to cell trans-differentiation from one cell phenotype to another. ${ }^{[62]}$ Co-culturing of different cell types is a useful technique to integrate the different tissue regions of the soft tissue-to-bone interface.

An alternative to using multiple cell types is using MSCs, which can differentiate into multiple cell types. In vivo entheses begin as dense mesenchymal condensates and develop into complex interfaces. ${ }^{[90-92]}$ Since MSCs have the capacity to differentiate into all the cell phenotypes of the enthesis, MSCs are a logical cell source to use for tissue engineering the enthesis. ${ }^{[93,94]}$ MSCs from bone marrow (bmMSCs) are a popular source for tissue engineering, because they are easily obtained and expanded. Adipose-derived stem cells (ASCs) are another common stem cell source. Since ASCs are easily obtained from fat which is considered surgical debris, they are the most readily available stem cell source from human tissue. While ASCs do have multi-potent properties, they have been shown to be less effective than bmMSCs at differentiating into cartilage and bone. ${ }^{[95]}$ Stem cells seeded into tissue engineered enthesis constructs rely on mimicking the biomaterial and biochemical inputs that direct differentiation during development. For example, regional changes in pore alignment of a tendon/ligament enthesis silk fibroin scaffold resulted in corresponding ASC differentiation into cartilage and tendon lineages [Fig. 6 (a).$^{[58]}$ These examples emphasize the importance of scaffold material and biochemical design in order to inform cell behavior when generating enthesis constructs.

Construct geometry and chemistry have been shown in multiple systems to affect cellular phenotype through cell-material interactions. ${ }^{[96,97]}$ Cellular phenotypes can be dictated by cellmaterial interactions. A material such as collagen has cellular adhesion sites, allowing cells to bind and spread, encouraging the cells to develop a fibroblastic morphology. Alternatively, a material lacking in cell adhesion sites, like alginate, prevents cells from binding, encouraging a chondrogenic morphology. ${ }^{[98,99]}$ Cell morphology, such as a fibroblastic or chondrogenic morphology, has been shown to be an indicator for cell behavior and matrix production. ${ }^{[100]}$ Scaffold mechanical properties are known to direct stem cell fate, where materials with stiffer structures promote osteogenic differentiation. ${ }^{[101,102]}$ Lastly, chemical composition dictates cellular response. Cells embedded in a proteoglycan-rich region experience increased strain shielding compared to cells embedded in collagen fibers when a tissue-level mechanical deformation is applied to the scaffold. ${ }^{[72]}$ Furthermore, the arrangement and alignment of fibers in a 3D microenvironment affects cellular behavior and the distribution of applied loads. In an aligned poly(ethylene oxide) scaffold, cells attach and elongate in the direction of the fibers. Fiber alignment aided bmMSC differentiation into a fibrous phenotype compared with the same bmMSCs in pellet culture which developed a chondrogenic phenotype. ${ }^{[100]}$ Furthermore, aligned fibers improved ligamentous phenotype, as cells develop characteristic spindle shapes and increase production of collagen when compared with random fiber alignment. The alignment of fibers also affects the cellular response to an applied strain, with longitudinal strains in the fiber direction inducing the largest increase in collagen production. ${ }^{[103,104]}$ These studies emphasize the importance of material mechanical properties and structure when considering cellular interactions and response.

Another approach to tissue engineering soft tissue-to-bone interfaces shifts the focus from materials design to utilizing the cells themselves to create the scaffold. Cells grown in monolayers have the ability to proliferate to fill the surface area and then self-assemble to form their own matrix. A multicomponent bone-ligament-bone tissue engineered anterior cruciate ligament (ACL) graft was created using confluent cell monolayers [Fig. 6(b)]. The bmMSCs were first predifferentiated into ligamentous or bone pathways in monolayer and then assembled together into a 3D scaffold. The resulting scaffold showed sufficient properties for ACL replacement and performed well during long-term implantation in an ovine model. ${ }^{[68]}$ Gene transfer is another strategy to spatially regulate genetic modification and differentiation of primary dermal fibroblasts. A retrovirus encoding the factors RUNX2 and cbfal was used to induce osteoblastic and fibroblastic differentiation, respectively. ${ }^{[105]}$ These techniques demonstrate that cells can be used to produce complex gradients for soft tissue-to-bone interfaces.

\section{Biochemical factors}

A range of biochemical factors can influence production and remodeling of ECM by cells. Growth factors are proteins that are secreted by cells and act as signaling molecules to other cells via cell surface receptors. These molecules play active roles in establishing the complex structure of the enthesis, healing the tissue after injury, and maintaining tissue homeostasis. This section highlights relevant biochemical signals in development and their application to enthesis tissue engineering.

\section{Native biochemical signaling}

Soft tissue-to-bone interfaces have a wide array of growth factors that influence cellular activities such as differentiation, proliferation, apoptosis, and matrix production. Key growth factor contributors to bone growth, repair, and differentiation are bone morphogenic proteins (BMPs), transforming growth factor- $\beta \mathrm{s}$ (TGF- $\beta \mathrm{s}$ ), and insulin-like growth factors (IGFs) (Table I). ${ }^{[106-108]}$ The growth plate contains similar regional zones to the enthesis since it is an interface between bone and cartilage. Growth factors secreted in the growth plate are essential to endochondral bone formation and include IGFs, Indian hedgehog (Ihh), parathyroid hormone-related peptide (PTHrP), BMPs, Wnts, fibroblast growth factors (FGFs), and TGF- $\beta$ s. ${ }^{[76]}$ Key players in bulk tendon and ligament development, healing, and remodeling are IGFs, growth and 
Table I. Growth factors commonly used in orthopedic tissue engineering applications. See the following reviews for more on specific growth factors. ${ }^{[108-110,112]}$

\begin{tabular}{|c|c|c|c|c|c|c|c|c|}
\hline \multicolumn{7}{|c|}{ Native expression } & \multicolumn{2}{|r|}{ Tissue engineering applications } \\
\hline $\begin{array}{l}\text { Growth } \\
\text { plate }\end{array}$ & Bone & Tendon & Ligament & Cartilage & Meniscus & Growth factor & Isoform & Effect \\
\hline \multirow[t]{3}{*}{$x$} & $\mathrm{x}$ & & & $\mathrm{x}$ & & $\begin{array}{l}\text { Bone morphogenic proteins } \\
\text { (BMPs) }\end{array}$ & BMP-2 & $\begin{array}{l}\text { Stem cell proliferation and differentiation into } \\
\text { osteoblasts }{ }^{[50,54,69,113,114]} \\
\text { Stimulate bone formation and mineralization }{ }^{[50,113-116]}\end{array}$ \\
\hline & & & & & & & BMP-6 & $\begin{array}{l}\text { Enhance effect of TGF- } \beta 3^{[117]} \\
\text { Increase collagen production }{ }^{[89]}\end{array}$ \\
\hline & & & & & & & BMP-7 & Stimulate bone formation and mineralization ${ }^{[118]}$ \\
\hline \multirow[t]{3}{*}{$x$} & $\mathrm{x}$ & $x$ & $x$ & $x$ & $x$ & $\begin{array}{l}\text { Transforming grown factor }-\beta \\
\quad(\text { TGF- } \beta \text { ) }\end{array}$ & TGF- $\beta 1$ & $\begin{array}{l}\text { Encourages chondrogenesis }{ }^{[54,119,120]} \\
\text { Increased production of collagen and GAGs }{ }^{[54,121-123]} \\
\text { Increases proliferation }{ }^{[122,124,125]} \\
\text { Under certain conditions can be osteogenic and } \\
\quad \text { associate with hypertrophy }{ }^{[50,124,126]}\end{array}$ \\
\hline & & & & & & & TGF- $\beta 3$ & $\begin{array}{l}\text { Encourages chondrogenesis }{ }^{[71,81,89,94,127]} \\
\text { Increased production of collagen and } \\
\quad \text { GAGs }^{[71,81,89,94,117,127]} \\
\text { Enhance hypertrophic chondrocyte phenotype }{ }^{[126]}\end{array}$ \\
\hline & & & & & & $\begin{array}{l}\text { Growth and differentiation } \\
\text { factor (GDF) }\end{array}$ & GDF-5 & $\begin{array}{l}\text { Encourages chondrogenesis and tenogensis Increased } \\
\text { ECM deposition }{ }^{[128,129]}\end{array}$ \\
\hline$x$ & $\mathrm{x}$ & $x$ & $x$ & $x$ & $?$ & Insulin-like growth factor & IGF-I & $\begin{array}{l}\text { Stimulates proteoglycan synthesis }{ }^{[123,130,131]} \\
\text { Enhances effect of TGF- } \beta 3^{[117]}\end{array}$ \\
\hline $\mathrm{X}$ & $x$ & $x$ & $x$ & $x$ & $?$ & $\begin{array}{l}\text { Fibroblast growth factor } \\
\text { (FGF) }\end{array}$ & $\begin{array}{l}\text { Basic FGF bFGF or } \\
\text { FGF-2 }\end{array}$ & $\begin{array}{l}\text { Enhances proliferation }{ }^{[122,132]} \\
\text { Enhances chondrogenesis }^{[122]} \\
\text { Increases collagen production }{ }^{[132]}\end{array}$ \\
\hline$x$ & $x$ & $x$ & $x$ & $x$ & $x$ & $\begin{array}{l}\text { Platelet-derived growth factor } \\
\text { (PDGF) }\end{array}$ & PDGF-BB & $\begin{array}{l}\text { Enhances proliferation }{ }^{[132]} \\
\text { Enhances tenogenesis }^{[69]} \\
\text { Boost ECM deposition for tendon and ligament } \\
\quad \text { regeneration }{ }^{[69,132,133]}\end{array}$ \\
\hline$x$ & $x$ & $x$ & $x$ & & $x$ & $\begin{array}{l}\text { Vascular endothelial growth } \\
\text { factor (VEGF) }\end{array}$ & VEGF & $\begin{array}{l}\text { Increases vascularization }{ }^{[114]} \\
\text { Enhances bone formation }\end{array}$ \\
\hline
\end{tabular}

? indicates that no native study on these growth factors has been performed; however, TE applications have been performed using these growth factors and they are believed to play a role. 
differentiation factors (GDFs), TGF- $\beta$ s, vascular endothelial growth factor (VEGF), platelet-derived growth factor (PDGF), and FGFs. ${ }^{[109,110]}$ IGFs, FGFs, TGF- $\beta$ s, and PDGF are the central growth factors that contribute to developing and maintaining organized collagen structures and high levels of proteoglycans in cartilage and meniscus. ${ }^{[111]}$ While many of these growth factors are present in all of these tissues (Table I), the spatial and temporal expression of growth factors are important drivers of tissue development.

TGF- $\beta$ s, GDFs, BMPs, and IGFs regulate bone and joint development by influencing stem cell differentiation, matrix synthesis and remodeling, and cellular migration and proliferation. The TGF- $\beta$ superfamily is a group of structurally related proteins including TGF- $\beta \mathrm{s}$, GDFs, and BMPs that influence a broad range of activities in musculoskeletal development. Members of the BMP family encourage stem cell proliferation and differentiation into osteoblasts. ${ }^{[134,135]}$ Furthermore, BMPs are osteoinductive, encouraging bone formation and maintenance by recruiting bone-forming cells that result in the formation of mineralized bone. BMPs have successfully navigated the FDA approval process for bone healing applications, notably BMP-2 (Infuse ${ }^{\circledR}$ Medtronic) and BMP-7 (also called OP-1 by Stryker). ${ }^{[136]}$ GDFs, specifically GDF-5, interact closely with BMPs and act as signaling molecules in the growth and differentiation of cartilage, tendon, and ligament. ${ }^{[128,129,137-139]}$ TGF- $\beta$ s are prevalent in all of these tissues and are known to play a role in proliferation and stem cell differentiation. ${ }^{[140]}$ In particular, TGF- $\beta$ is heavily implicated for its role in chondrogenic differentiation and development. ${ }^{[141,142]}$ IGF is a regulator of longitudinal bone growth in that it stimulates osteoblast proliferation and differentiation as well as increasing general cell proliferation and ECM synthesis. ${ }^{[143-146]}$ These growth factors are essential signaling contributors to stem cell differentiation and tissue development in native orthopedic tissues.

Several growth factors prevalent in the inflammatory and healing processes also aid in the production of tissue. Vascularization-related growth factors are important in soft tissue development and healing; common growth factors include PDGF and VEGF. ${ }^{[54,108,110,132,147-149]}$ Basic fibroblastic growth factor (FGF-2) is known to contribute to cell proliferation and is expressed in the developmental and healing phases of these tissues. ${ }^{[132,135]}$ Growth factors have been specifically targeted for tissue engineering applications, because they are exogenously secreted factors that can be dosed into a system with relative ease and can drive stem cell differentiation and tissue maintenance.

\section{Biochemical applications in tissue engineering}

Since growth factors are known to play influential roles in cell behavior, they have been frequently applied to tissue engineer bone, cartilage, meniscus, tendon, and ligament (Table I). BMPs are popular for tissue engineering applications in bone interfaces and have been shown to induce mineralization as well as to stimulate osteoblast proliferation in scaffolds. ${ }^{[115,124,136]}$ Scaffolds doped with IGF-I increased cartilage regeneration in growth plate injuries in vivo and increased the collagen and GAG content in tissue engineered cartilage constructs in vitro. ${ }^{[130,150,151]}$ VEGF was incorporated into a mineralized degradable polymer scaffold to provide osteoconductive signals for bone growth and angiogenesis. ${ }^{[152]}$ GDFs increased type I collagen production in 3D tissue engineered scaffolds. ${ }^{[128,129]}$ TGF- $\beta$ s increase GAG and collagen production which improves the quality of tissue engineered cartilage and meniscus. ${ }^{[81,121,125,153]}$ Growth factors provide signaling mechanisms to encourage cellular components to exhibit a specific phenotype.

Prominent growth factors in these developmental processes can also guide stem cell differentiation in tissue engineered constructs. BMP-2 combined with hydroxyapatite in a silk fibroin fiber scaffold supported MSC growth and differentiation toward an osteogenic phenotype, quantified by increased BMP-2 transcription levels and mineral deposition. ${ }^{[13]}$ Delivering BMP-2 and BMP-7 sequentially increased ALP activity while suppressing proliferation of MSCs, ${ }^{[118]}$ highlighting the potential for benefits from temporal application of biochemical factors to cells. Growth factor delivery using a scaffold can increase efficiency of stem cell differentiation into a desired cell phenotype. Localized delivery of IGF in a PLGA scaffold increased MSC chondrogenesis in vitro, ${ }^{[150]}$ while FGF- 2 and TGF- $\beta 1$ increased chondrogenesis of periosteum derived cells. ${ }^{[122]}$ GDF-5 supplemented medium as well as GDF-5 induction by adenovirus increased expression of type I collagen and scleraxis, associated with tenogensis, in stem cells seeded on a 3D scaffold. ${ }^{[128,129]}$ TGF- $\beta 3$ conjugated with chondroitin sulfate increased MSC chondrogenic differentiation by increasing GAG production and expression of Sox9, COMP, aggrecan, and type II collagen genes. ${ }^{[71]}$ Controlled release of TGF- $\beta 3$ also promoted chondrogenesis of human infrapatellar fat pad-derived stem cells, measured by increased production of sulfated GAGs and collagen. ${ }^{[127,154]}$

Growth factors are useful chemical tools for generating complex materials gradients. Since growth factors can be incorporated into a biomaterial, they can be strategically placed or applied to influence cellular behavior in controlled chemical gradients for soft tissue-to-bone tissue engineering. BMP-2, delivered using microspheres in a poly(propylene fumarate) scaffold, increased bone regeneration and ACL graft fixation. ${ }^{[16]}$ An integrated gradient of BMP-2 and TGF- $\beta 1$ has been shown to create a continuous material and phenotypic transition between cartilage and bone. ${ }^{[50,54]}$ Application of growth factors is especially favorable when using a single progenitor cell type in the scaffold. Rather than seeding multiple cell types, growth factors can be incorporated to initiate the differentiation of stem cells. ASCs, seeded in a porous PCL/ Pluronic F127 membrane with gradients of PDGF, specifically PDGF-BB (tendon) and BMP-2, created a continuous interface between tendon and bone, with PDGF promoting tenogenesis and BMP-2 promoting osteogenesis [Fig. 6(c)]. ${ }^{[69]}$ In combination with materials processing methods and cells, growth factor 
gradients contribute to the development of integrated and graded regions for engineered soft tissue-to-bone interfaces.

In addition to facilitating cell-biochemical interactions, growth factors can be sequestered by ECM proteins. Proteoglycans function as physiologic regulators by sequestering growth factors and controlling release. SLRPs, such as biglycan, decorin, and fibromodulin, are capable of binding to TGF- $\beta$ and are likely to regulate the availability of TGF- $\beta$ to cells. ${ }^{[155]}$ While the exact mechanism is not well understood, increased levels of type II collagen in a scaffold enhance the effect of TGF- $\beta$ on chondrocytes. ${ }^{[156]}$ FGFs bind to heparan proteoglycans in the ECM. For example, perlecan, a heparan sulfate proteoglycan, co-localizes with FGF thus regulating FGF availability to cell receptors. ${ }^{[157]}$ Availability of BMP-2 is regulated through sequestering with heparin and type IIA procollagen. ${ }^{[158,159]}$ Biomaterials, such as alginate, have been modified with binding peptides that specifically bind a growth factor in order to sustain growth factor availability over longer culture periods. ${ }^{[130]}$ The ability of ECM proteins to regulate growth factor availability contributes to the highly complex interplay of materials, cells, and biochemical signaling in a tissue engineered construct but also allows for the engineered regulation of cellular behavior and scaffold maturation.

Biomaterials combined with growth factors can act as powerful chemoattractants. Growth factors, connective tissue growth factor (CTGF) and TGF- $\beta 3$, seeded onto a tissue engineered scaffold encouraged cellular recruitment and regionspecific cell morphology in the meniscus. ${ }^{[81]}$ Decellularization techniques preserve the material structure and resident biochemical components that can be used as a fully functional scaffold. ${ }^{[160]}$ Decellularized and demineralized bone matrix applied to the tendon-to-bone surgical suture site improved tendon-to-bone healing, demonstrated through increased amounts of fibrocartilage and mineralized fibrocartilage in the repair site enthesis and reduced rates of tendon failure. ${ }^{[64]}$ Recent work has successfully decellularized the entire tendon-to-bone insertion, ${ }^{[63]}$ with significant improvements in pullout strength using the decellularized tendon-to-bone insertion over the direct suture technique. ${ }^{[161]}$ Cells were able to repopulate the graft and exhibited a transition from a cartilagelike to tenocyte-like morphology across the interface. ${ }^{[161]}$ Biomaterials and growth factors together serve as promising tissue engineered scaffolds that rely on cell repopulation after in vivo implantation.

\section{Construct maturation}

After producing a viable, chemically active, cell-seeded scaffold, the maturation of the scaffold must be driven through external stimuli, either in vitro or in vivo (Fig. 5). In the body, chemical and mechanical signals guide development. Mechanical loading of the tissue helps to direct proper enthesis development, as immobilization during development results in altered enthesis geometry and significantly decreased mechanical properties. ${ }^{[162]}$ As described in the "Biochemical factors" section, various biochemical factors affect the differentiation of cells in different regions of the enthesis. These biochemical factors can be engineered into a scaffold with a controlled release over time or can be supplemented into culture media utilizing diffusion to create stimulation gradients. Given these two factors, this section discusses culture methods and bioreactor designs for driving proper maturation using chemical and mechanical stimulation.

\section{Chemically driven maturation}

Chemical means of driving cell maturation typically occur through media supplementation. In the case of the enthesis, bone media, cartilage media, ligamentous/tendinous media, and meniscal media are typically used individually or in combination. The majority of osteogenic media contains $\beta$-glycerophosphate and dexamethasone, ${ }^{[52,55,68,163-165]}$ with some including BMP-2 ${ }^{[163,165]}$ and TGF- $\beta .^{[68]}$ Dexamethasone is also included in some chondrogenic media, ${ }^{[126,164,165]}$ while TGF- $\beta$ is often used in media for the soft tissue portions of the enthesis. ${ }^{[52,68,126,163-165]}$ Dexamethasone is a glucocorticoid that has been shown to increase ALP activity in MSCs. ${ }^{[166]}$ $\beta$-Glycerophosphate is an organic phosphate donor classically used to induce MSC differentiation toward bone phenotypes. ${ }^{[52,163,167,168]}$ Application of $\beta$-glycerophosphate at the interface of a calcium polyphosphate substrate cultured with chondrocytes formed two zones, a calcified region between a calcium phosphate bony substrate and a hyaline cartilage-like zone. ${ }^{[45]}$ Furthermore, combining $\beta$-glycerophosphate and BMP-2 in the bone region of an osteochondral scaffold directed stem cell osteogenesis. ${ }^{[124]}$ Ascorbic acid and L-proline are added to media to promote collagen production. Ascorbic acid or ascorbate-2-phosphate (a format used to stabilize ascorbic acid in solution) ${ }^{[169]}$ has been shown to increase the hydroxylation rate of proline, ${ }^{[170]}$ aiding in collagen production. These chemical stimulants can be incorporated into the scaffold design to enhance a desired cell behavior either through direct interaction with cells or complementary mechanisms to other growth factors or ECM materials present in the scaffold.

Many of the relevant published systems have been produced for the osteochondral interface, given its similarity to other soft tissue-to-bone interfaces. The majority of systems designed to promote interface formation in culture rely on diffusion-based bioreactors; the general principle being that bone phenotypepromoting media and soft tissue phenotype-promoting media will diffuse through the construct, meet in the middle, and facilitate the formation of an interface. ${ }^{[61,164,165,171]}$ Using this concept, a microfluidic bioreactor directed MSC differentiation along osteogenic and chondrogenic pathways in parallel [Fig. 7(a)]. The bioreactor consisted of an MSC-seeded agarose gel sandwiched between two other MSC-seeded agarose gels that contained channels. The channel-containing gels are perfused with osteogenic and chondrogenic media, respectively, creating a tri-layered scaffold with an interfacial region. This system produced gradients from the osteogenic to chondrogenic regions: decreasing type I collagen content, increasing type II collagen content, and decreasing Alizarin Red staining, reflecting decreasing matrix-immobilized calcium content. 

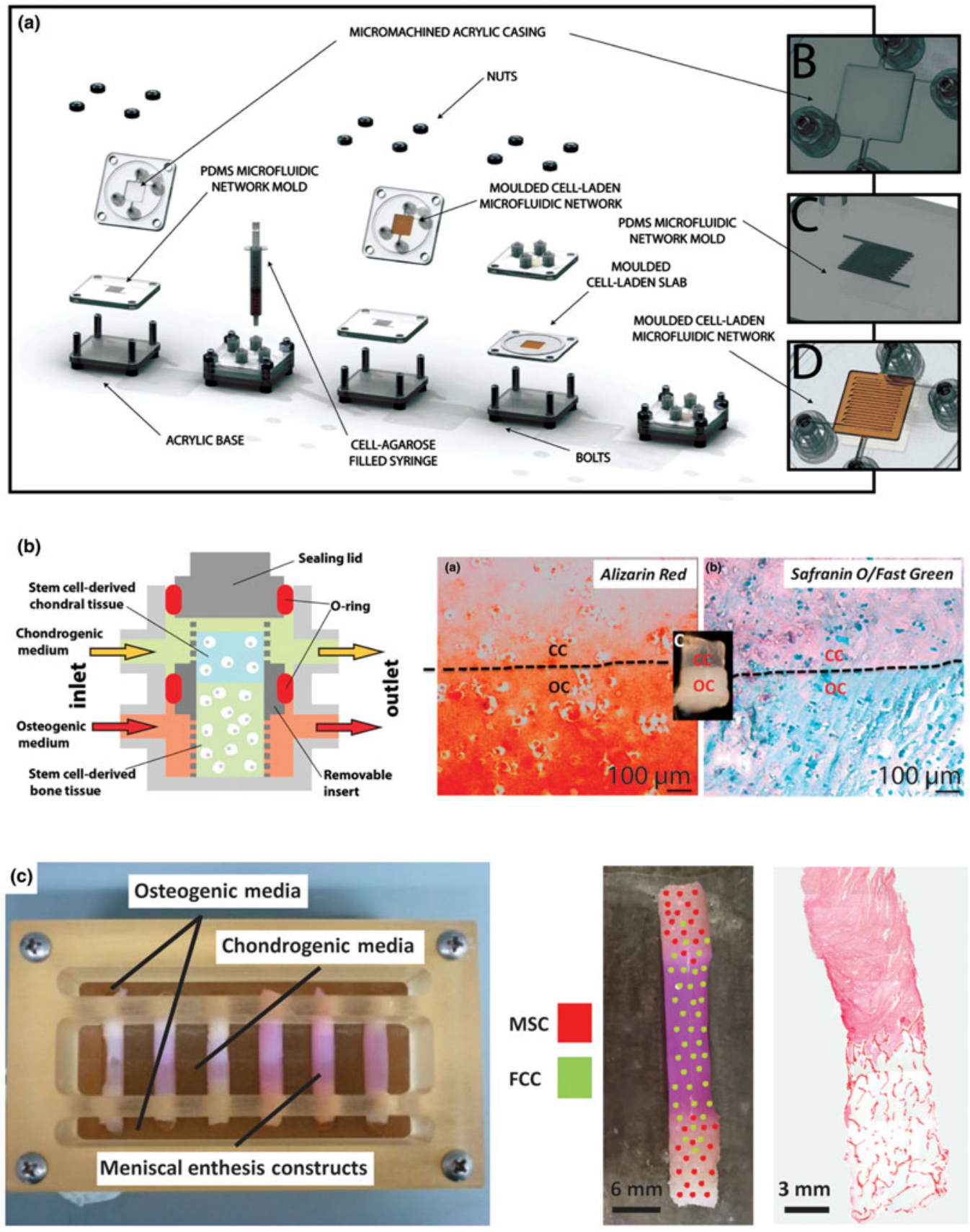

Figure 7. Examples of bioreactor designs for maturation of tissue engineering interfacial tissues. (a) Osteochondral microfluidic bioreactor. ${ }^{[172]}$ This bioreactor creates two microchannel arrays in a gel, separated by a non-channel gel slab in the center. Osteogenic and chondrogenic media are flowed through the microchannels allowing for diffusion into surrounding walls and through central slab, creating an interfacial construct. Reprinted with permission from Stephen M. Goldman, Gilda A. Barabino, Cultivation of agarose-based microfluidic hydrogel promotes the development of large, full-thickness, tissue-engineered articular cartilage constructs, John Wiley and Sons. Copyright (C) 2014 John Wiley \& Sons Ltd. ${ }^{[172]}$ (b) Osteochondral bioreactor. ${ }^{[163]}$ Chondrogenic and osteogenic media are continuously flowed through a scaffold, while maintaining separation of media baths through use of an 0-ring. Histology shows interfacial region for construct: chondral component (CC) and osseous component (OC). Alizarin red stains for calcium, Safranin-0 stains for negatively charged molecules (GAGs), and fast green stains for proteins. This schematic was reprinted from <http://pubs.acs.org/doi/abs/10.1021/mp500136b>. Further permissions related to the material excerpted should be directed to the ACS. ${ }^{[163]}$ (c) Combination mechanical, chemical, and co-culture bioreactor for culturing meniscal enthesis constructs. These constructs consist of two bone plugs seeded with mesenchymal stem cells (MSCs) injected and connected with a high density collagen gel embedded with meniscal fibrochondrocytes (FCCs). The bone plugs are anchored down in the bioreactor using the walls, and then osteogenic media and meniscal media can be applied to different portions of the scaffold. Image shows distribution of co-cultured cells on constructs, and histology shows the morphology of the interfacial region of the construct (images courtesy of Leanne lannucci). Reprinted from Acta Biomaterialia, Volume 56, Mary Clare McCorry, Melissa M. Mansfield, Xiaozhou Sha, Daniel J. Coppola, Jonathan W. Lee, Lawrence J. Bonassar, A model system for developing a tissue engineered meniscal enthesis, 110-117, Copyright (C) 2016, with permission from Elsevier ${ }^{[60]}$ 
These gradients indicate that interfacial regions can be formed by supplying one cell type with different medias and flow conditions simultaneously [Fig. 7(a)] ${ }^{[165,172]}$ Flow of chondrogenic and osteogenic media through the top and bottom of a singular osteochondral scaffold, while maintaining media separation around the scaffold using an O-ring, produced distinctive corresponding regions [Fig. 7(b)]. Osteochondral scaffolds were produced by pipetting a chondrogenic, photo-crosslinked, cell-seeded gel onto an osteogenic, photo-crosslinked, cellseeded gel. Chondrogenic gels consisted of MSC-seeded methacrylated gelatin with hyaluronic acid and a photo-crosslinker (lithium phenyl-2,4,6-trimethylbenzoylphosphinate). Osteogenic gels had a similar composition, except with hydroxyapatite rather than hyaluronic acid. After 4 weeks of culture, the corresponding sections of the osteochondral construct showed heightened expression of chondrogenic and osteogenic markers. The construct also contained a junction between the sections of the scaffold, with visible GAG staining in the chondrogenic portion and calcium staining in the osteogenic portion [Fig. 7(b)]. ${ }^{[163]}$

\section{Mechanically driven maturation}

The native enthesis sustains dynamic tensile, compressive, and shear loading that contributes to the development of the integrated regions. The structural transition from soft tissueto-bone promotes gradual load transfer across the interface, indicating the importance of the structure-function relationship in the enthesis. ${ }^{[1,26,173]}$ The native enthesis contains a dense network of collagen fibers interdigitated into bone that aid in tensile and compressive load transmission. ${ }^{[174-177]}$ The loading environment of the enthesis provides mechanical cues to cells that instruct matrix production and remodeling. Lack of loading during native development results in impaired mineral deposition and disorganized fiber distribution. ${ }^{[178]}$ In the case of healing after tendon injury, immobilization actually increased structural, compositional, and viscoelastic properties compared with an exercised group. ${ }^{[179]}$ Considering the mechanical influences on tissue development is important when designing methods for tissue engineered enthesis maturation.

During development, anchoring of the meniscus to the tibia produces a static mechanical boundary condition that triggers longitudinal fiber organization in the soft tissue. ${ }^{[90-92,180]}$ Mimicking this static mechanical boundary condition has shown organized fiber remodeling from several cell types including fibroblasts, ${ }^{[181-184]}$ MSCs, ${ }^{[185-187]}$ cardiomyocytes, ${ }^{[184]}$ annulus fibrosis chondrocytes, ${ }^{[188]}$ and meniscal fibrochondrocytes. ${ }^{[60,74,86]}$ Mechanical anchoring at the bony ends of a soft tissue-to-bone model system directed longitudinal fiber formation as well as formed interdigitated fibers at the collagen-bone interface [Fig. 7(c)] ${ }^{[60]}$ Cell monolayers mechanically fixed at the end points contracted the cell sheet into a 3D construct. Using this method, the cells organized a highly aligned and integrated enthesis for ACL repair [Fig. 6 (b)]. ${ }^{[68]}$ While mechanically directed fiber remodeling has been shown in several systems, different cell types have also displayed varying levels of remodeling capability. When tendon and meniscal fibrochondrocytes were embedded in a collagen matrix and clamped, fibrochondrocytes formed significantly larger fibers than tendon cells. ${ }^{[189]}$ MSCs in a tissue engineered meniscus also showed decreased fiber alignment and diameter compared with fibrochondrocytes. ${ }^{[86]}$ These studies indicate that the response to mechanical stimuli is highly dependent on cell type.

Active mechanical loading is applied to enthesis tissues in vivo, and these active mechanical signals guide differential tissue formation. While active mechanical loading has not been applied to in vitro enthesis tissue engineering yet, other systems have utilized active loading. Bioreactors have been designed to apply uniaxial tensile loads in bulk ligament and tendon tissue engineering (constructs excluding an enthesis). ${ }^{[103,104]}$ After tensile loading of an aligned scaffold seeded with MSCs, type I and III collagen expression increased as did expression of fibroblastic markers, including tenascin-C, fibronectin, and integrins $\alpha_{2}, \alpha_{5}$, and $\beta_{1} \cdot{ }^{[104]}$ Simultaneous tensile and compressive stimulation by compressively loading a self-assembled meniscus ring, resulted in significant increases in mechanical and biochemical properties. ${ }^{[190]}$ This effect was further demonstrated by loading mechanically anchored tissue engineered menisci. Dynamic compressive loading of the meniscus enhanced organized collagen fiber formation, mechanical properties, and GAG accumulation. Mimicking native mechanical loads guided heterogeneous tissue development, where tensile loads in the outer meniscus produced a fiber-containing, collagen-rich tissue, and compressive loads on the inner meniscus increased GAG development. ${ }^{[191]}$ The native environment can also serve as a natural load inducer to guide tissue maturation, assuming the construct is robust enough for implantation. A cell self-assembled bone-ligament-bone construct underwent marked increases in collagen content and alignment as well as increases in stiffness after implantation, driving biochemical content and mechanical properties toward native ACL. ${ }^{[68]}$ These studies collectively support active mechanical stimulation as a useful tool to the drive structural development of tissue engineered constructs.

\section{Looking forward}

The field of orthopedic interfacial tissue engineering presents a number of exciting opportunities for pushing forward the fields of biomaterials, tissue engineering, and biomechanics. In the coming years, advances are required in our understanding of both the in vivo function and generation of entheses, as well as in our capabilities to engineer constructs to replace these complex tissues. Specifically, we have identified three areas of opportunity to inform the design and development of next generation tissue engineered entheses: (1) understanding the development and homeostasis of the native enthesis, (2) development of new materials and bioreactors for enthesis engineering, and (3) mechanical and structural verification of tissue engineering and implant success. 
1. Understanding the Development and Homeostasis of Native Entheses

(a) Structure-function relationships, specifically at the length scales critical for the function of this hierarchically structured tissue (Fig. 3), remain poorly understood in the native enthesis. Improving our understanding of how specific molecular, cellular, and architectural features contribute to the healthy function of entheses, requires correlative compositional and mechanical data collected with micrometerscale resolution. In addition to high-resolution data sets, these measurements need to be performed on hydrated tissue samples under physiologically relevant conditions. This type of characterization will require the development of creative imaging strategies that correlatively combine multiple techniques capable of providing chemical, structural, and mechanical information on the same piece of tissue. ${ }^{[192]}$

(b) Various proteins and molecules are present in low concentrations throughout the regions of the enthesis (e.g., non-collagenous proteins in bone, type X collagen in mineralized cartilage, SLRPs in areas with oriented collagen fiber bundles), but the specific functional roles of these macromolecules are largely unknown. For example, the exact function of noncollagenous proteins in bone is unknown given the redundant roles of these proteins in bone formation. Therefore, the cause of irregularities is hard to characterize using knockout models of non-collagenous proteins. ${ }^{[39]}$ Studies examining the roles of these molecules in the formation of these regional structures, either through knockout models or in vitro concentration studies, will allow for tissue engineers to target specific results (fibers with controlled diameters, fibrocartilage formation, etc.) to create integrated, biomimetic constructs.

(c) Tendon, ligament, cartilage, and bone cell phenotypes have been well characterized independently (Fig. 4), but the enthesis incorporates these phenotypes in overlapping gradients, which makes specific phenotypic categorization challenging. Spatial characterization of cell phenotypes within the enthesis is needed to define concrete objectives regarding cell seeding and localized stem cell differentiation. While differentiation into bone and cartilage is well studied, less is known about appropriate inputs for fibrochondrocyte and hypertrophic fibrochondrocyte differentiation.

(d) Growth factors play an essential role in the development and maintenance of the enthesis; however, limited information exists regarding spatial and temporal expression of growth factors in developing and mature entheses. Additionally, growth factors have complex interactions with each other and the ECM that complicate the study of each one's exact role. Further study should focus on characterizing the spatial and temporal frequencies of expression of growth factors in vivo, thereby generating a greater understanding of the time- and length-scales over which growth factors must be applied to drive cellular differentiation in tissue engineered constructs.

2. Develop New Materials and Bioreactors for Entheses Engineering

(a) Hierarchical structures within the native tissue give rise to mechanical, cellular, and biochemical cues critical to healthy tissue function. However, generating biomaterials with similar types of hierarchical structuring remains a challenge and requires extensive control over assembly at various length scales. New synthetic approaches need to be developed that can create materials with the critical features of the native tissue (e.g., strategic biomimicry) and that are scalable. ${ }^{[66]}$ This task can only be accomplished by both understanding the native structures and evaluating which features are critical for a given function. Once key hierarchical structures are identified and synthetic methods have been developed, then new biomaterials can be designed to possess many of the same properties that native tissue benefits from in vivo.

(b) The range of materials properties (e.g., several orders of magnitude change in stiffness on the order of $<1$ $\mathrm{mm}$ ) in the enthesis presents unique challenges in creating a graded interface. In order for a tissue engineered construct to be mechanically robust, differing materials must be fully integrated, utilizing concentration gradients, interpenetrating materials, etc., to avoid stress concentrators at the point of material interface. A specific challenge in this regard is the design of structures with partially mineralized collagen fibers or gradients in alignment and fiber diameter to help anchor soft tissue to bone.

(c) Current designs of bioreactors for interfacial tissue constructs have been utilized to apply spatially controlled stimuli (Fig. 7). However, the effects of changing the application profile, e.g., a linear gradient versus a step function, of a chemical stimulus on a tissue engineered construct are not well understood. Moving forward, researchers should focus on finer spatial control. Such experiments will increase understanding of the interactions of different chemical stimuli, leading to more refined systems for controlling local cellular behavior.

3. Improve Mechanical and Structural Verification of Tissue Engineering and Implant Success

(a) The baseline mechanical properties (e.g., toughness, stiffness, and failure strain) required for enthesis construct implantation have not been identified. Baseline properties are largely unknown and likely vary significantly with anatomic location. Such mechanical benchmarks would provide engineers with a more concrete goal to work towards when developing 
constructs. Devices for measuring native load distributions exist, ${ }^{[193]}$ and similar devices should be developed and utilized in these systems to inform design criteria.

(b) The mechanical behavior of the enthesis is non-linear and heterogeneous. As such, properties and test protocols used to describe the mechanics of linear elastic materials do not fully describe the behavior of these tissues. For example, cyclic loading would provide information on viscoelastic properties (e.g., storage modulus, loss modulus, and hysteresis) and would provide information on the fatigue life of such constructs. Tissue is frequently loaded cyclically in vivo, following gait cycles or other repetitive motions. Therefore, the properties of these tissues during cyclic loading need to be explored to validate implant viability.

(c) In addition to mechanical characterization, analysis of the structure of the enthesis provides a great opportunity for the development of new techniques. The presence of orientation and heterogeneity necessitates the development or adaptation of techniques to highlight these features. Advances in magnetic resonance imaging of soft tissues includes pulse sequences such as ultrashort T2 echo times that highlight collagen orientation, ${ }^{[194]}$ but these techniques have not been applied to assess the structure or health of entheses. Additionally, while standard histological analyses enable semiquantitative assessment of spatial patterns of the components of the enthesis, mapping mineral, proteoglycan, and collagen requires different tissue processing methods, distinct stains, and multiple sections. Vibrational microspectroscopy methods enable detection of multiple chemical species at once through infrared absorption and Raman scattering. These techniques have been more frequently applied to bone, cartilage, tendon, and ligament than the entheses. ${ }^{[12,42,195,196]}$

As we capitalize on these opportunities and begin to answer these outstanding questions, we will increase our understanding of the native enthesis and, in return, be able to design the next generation of tissue engineered orthopeadic interfaces. Emerging technologies, such as gene therapy and induced pluripotent stem cells (iPSCs), ${ }^{[105]}$ provide new possibilities for engineering complex tissues. iPSCs are a clinically available cell source; however, precise control of cell differentiation remains a challenge. ${ }^{[197]}$ Gene therapy potentially allows for more direct control of cell differentiation, which is highly pertinent in systems containing many cell types. Other similar technologies, like CRISPR, ${ }^{[198]}$ have been unexplored in orthopedic systems and may be of great value for spatially guiding local differentiation to achieve desired phenotypic gradients. Additionally, as tissue engineering is a relatively new field, many of the materials processing methods that have been developed for other materials systems (electronic, structural, etc.) have not been applied to biologic systems. For example, the electronics industry has demonstrated nanometer-scale control over semiconductor systems using lithography. Some of these technologies have been translated to biologic systems, ${ }^{[199]}$ but the requirement of $3 \mathrm{D}$ structuring makes application of these techniques difficult. Other cutting edging processing methods, such as $3 \mathrm{D}$ printing, ${ }^{[200]}$ have been utilized to develop complex geometries for tissue engineering, but printing resolution needs to be improved in order to gain clinical viability for these constructs. Utilizing materials design principles external to the biologic fields could greatly benefit implant production. In the next 10 years, we will be able to demonstrate control over the assembly and culture of hierarchically structured living tissues for the repair of orthopedic soft tissue-to-bone interfaces.

\section{Acknowledgments}

The authors acknowledge support from the National Center for Advancing Translational Sciences (NCATS) grant TL1TR000459 of the Clinical and Translational Science Center at Weill Cornell Medical College, and A.J.B. acknowledges a pre-doctoral fellowship award (F31AR070009) from the National Institute of Arthritis and Musculoskeletal and Skin Diseases (NIAMS) of the National Institutes of Health (NIH). The authors would like to thank Leanne Iannucci, Benjamin Cohen, and Jongkil Kim for critical reading of the manuscript and Mary Lou Norman for preparing histological sections.

\section{References}

1. A.C. Abraham and T.L. Haut Donahue: From meniscus to bone: a quantitative evaluation of structure and function of the human meniscal attachments. Acta Biomater. 9, 6322-6329 (2013).

2. L. Mente and J.L. Lewis: Elastic modulus of calcified cartilage is an order of magnitude less than that of subchondral bone. J. Orthop. Res. 12, 637-647 (1994).

3. R.M. Schinagl, D. Gurskis, A.C. Chen, and R.L. Sah: Depth-dependent confined compression modulus of full-thickness bovine articular cartilage. J. Orthop. Res. 15, 499-506 (1997).

4. P. Brooks: Inflammation as an important feature of osteoarthritis. Bull. World Health Organ. 81, 689-690 (2003).

5. W.R. Shelton and A.D. Dukes: Meniscus replacement with bone anchors: a surgical technique. Arthrosc. J. Arthrosc. Relat. Surg. 10, 324-327 (1994).

6. E.A. Khetia and B.P. McKeon: Meniscal allografts: biomechanics and techniques. Sports Med. Arthrosc. 15, 114-120 (2007).

7. P.J. Yang and J.S. Temenoff: Engineering orthopedic tissue interfaces. Tissue Eng. B., Rev. 15, 127-141 (2009).

8. H.H. Lu and S. Thomopoulos: Functional attachment of soft tissues to bone: development, healing, and tissue engineering. Annu. Rev. Biomed. Eng. 15, 201-226 (2013).

9. S. Font Tellado, E. Rosado Balmayor, and M. Van Griensven: Strategies to engineer tendon/ligament-to-bone interface: biomaterials, cells and growth factors. Adv. Drug Deliv. Rev. 94, 126-140 (2015).

10. T.M. Hammoudi and J.S. Temenoff: Biomaterials for regeneration of tendons and ligaments. Biomater. Tissue Eng. Appl. 11, 307-341 (2011).

11. J. Gao, K. Messner, J. Ralphs, and M. Benjamin: An immunohistochemical study of enthesis development in the medial collateral ligament of the rat knee joint. Anat. Embryol. (Berl). 19, 399-406 (1996).

12. J.P. Spalazzi, A.L. Boskey, N. Pleshko, and H.H. Lu: Quantitative mapping of matrix content and distribution across the ligament-to-bone insertion. PLOS ONE. 8, e74349 (2013). 
13. S. Thomopoulos, G.M. Genin, and L.M. Galatz: The development and morphogenesis of the tendon-to-bone insertion. What development can teach us about healing. J. Musculoskelet. Neuronal Interact. 10, 35-45 (2010).

14. K. Messner and J. Gao: The menisci of the knee joint. Anatomical and functional characteristics, and a rationale for clinical treatment. $J$. Anat. 193, 161-178 (1998).

15. J. Gao: Immunolocalization of types I, II, and X collagen in the tibial insertion sites of the medial meniscus. Knee Surg. Sports Traumatol. Arthrosc. 8, 61-65 (2000).

16. W. Petersen and B. Tillmann: Structure and vascularization of the cruciate ligaments of the human knee joint. Anat. Embryol. (Berl). 200, 325334 (1999)

17. I-N.E. Wang, S. Mitroo, F.H. Chen, H.H. Lu, and S.B. Doty: Age-dependent changes in matrix composition and organization at the ligament-to-bone insertion. J. Orthop. Res. 24, 1745-1755 (2006).

18. M. Benjamin and J.R. Ralphs: The cell and developmental biology of tendons and ligaments. Int. Rev. Cytol. 196, 85-130 (2000).

19. G.M. Genin, A. Kent, V. Birman, B. Wopenka, J.D. Pasteris, P.J. Marquez, and S. Thomopoulos: Functional grading of mineral and collagen in the attachment of tendon to bone. Biophys. J. 97, 976-985 (2009).

20. P. Buma, N.N. Ramrattan, T.G. van Tienen, and R.P. Veth: Tissue engineering of the meniscus. Biomaterials 25, 1523-1532 (2004).

21. M.T. Rodrigues, R.L. Reis, and M.E. Gomes: Engineering tendon and ligament tissues: present developments towards successful clinical products. J. Tissue Eng. Regen. Med. 7, 673-686 (2013).

22. A. Di Luca, C.A. Van Blitterswijk, and L. Moroni: The osteochondral interface as a gradient tissue: From development to the fabrication of gradient scaffolds for regenerative medicine. Birth Defects Res. C 105, 34-52 (2015).

23. C. Vaquette, W. Fan, Y. Xiao, S. Hamlet, D.W. Hutmacher, and S. Ivanovski: A biphasic scaffold design combined with cell sheet technology for simultaneous regeneration of alveolar bone/periodontal ligament complex. Biomaterials 33, 5560-5573 (2012).

24. A.D. Waggett, J.R. Ralphs, A.P.L. Kwan, D. Woodnutt, and M. Benjamin: Characterization of collagens and proteoglycans at the insertion of the human Achilles tendon. Matrix Biol. 16, 457-470 (1998).

25. P. Fratzl and R. Weinkamer: Nature's hierarchical materials. Prog. Mater. Sci. 52, 1263-1334 (2007)

26. K.L. Moffat, W-H.S. Sun, P.E. Pena, N.O. Chahine, S.B. Doty, G.A. Ateshian, C.T. Hung, and H.H. Lu: Characterization of the structure-function relationship at the ligament-to-bone interface. Proc. Natl. Acad. Sci. U.S.A. 105, 7947-7952 (2008)

27. Y.X. Liu, S. Thomopoulos, V. Birman, J.S. Li, and G.M. Genin: Bi-material attachment through a compliant interfacial system at the tendon-to-bone insertion site. Mech. Mater. 44, 83-92 (2012).

28. G. Shen: The role of type $X$ collagen in facilitating and regulating endochondral ossification of articular cartilage. Orthod. Craniofacial Res. 8, 11-17 (2005)

29. T.E. Hardingham and A.J. Fosang: Proteoglycans: many forms and many function. FASEB J. 6, 861-870 (1992).

30. M. Benjamin and J.R. Ralphs: Fibrocartilage in tendons and ligaments —an adaptation to compressive load. J. Anat. 193(Pt 4), 481-494 (1998).

31. J. Melrose, S. Smith, M. Cake, R. Read, and J. Whitelock: Comparative spatial and temporal localisation of perlecan, aggrecan and type I, II and IV collagen in the ovine meniscus: An ageing study. Histochem. Cell Biol. 124, 225-235 (2005).

32. L. Rossetti, L.A. Kuntz, E. Kunold, J. Schock, H. Grabmayr, S.A. Sieber, R. Burgkart, and A.R. Bausch: The microstructure and micromechanics of the tendon-bone insertion. Nat. Mater. 16, 664-670 (2017).

33. H. Tavakoli Nia, L. Han, I. Soltani Bozchalooi, P. Roughley, K. Youcef-Toumi, A.J. Grodzinsky, and C. Ortiz: Aggrecan nanoscale solid-fluid interactions are a primary determinant of cartilage dynamic mechanical properties. ACS Nano. 9, 2614-2625 (2015)

34. A.K. Garg, R.A. Berg, F.H. Silver, and H.G. Garg: Effect of proteoglycans on type I collagen fibre formation. Biomaterials 10, 413-419 (1989).

35. K.G. Vogel and J.A. Trotter: The effect of proteoglycans on the morphology of collagen fibrils formed in vitro. Coll. Relat. Res. 7, 105-114 (1987).
36. K.G. Vogel, M. Paulsson, and D. Heinegård: Specific inhibition of type I and type II collagen fibrillogenesis by the small proteoglycan of tendon. Biochem. J. 223, 587-597 (1984).

37. E.J. Vanderploeg, C.G. Wilson, S.M. Imler, C.H.Y. Ling, and M.E. Levenston: Regional variations in the distribution and colocalization of extracellular matrix proteins in the juvenile bovine meniscus. J. Anat. 221, 174-186 (2012).

38. B. Wopenka and J.D. Pasteris: A mineralogical perspective on the apatite in bone. Mater. Sci. Eng. C 25, 131-143 (2005).

39. F. Nudelman, A.J. Lausch, N.A. Sommerdijk, and E.D. Sone: In vitro models of collagen biomineralization. J. Struct. Biol. 183, 258-269 (2013).

40. S. Weiner and H.D. Wagner: THE MATERIAL BONE: structure-mechanical function relations. Annu. Rev. Mater. Sci. 28, 271-298 (1998).

41. N. Reznikov, R. Shahar, and S. Weiner: Bone hierarchical structure in three dimensions. Acta Biomater. 10, 3815-3826 (2014).

42. A.G. Schwartz, J.D. Pasteris, G.M. Genin, T.L. Daulton, and S. Thomopoulos: Mineral distributions at the developing tendon enthesis. PLOS ONE 7, 1-11 (2012).

43. T.M. Keaveny, E.F. Morgan, G.L. Niebur, and O.C. Yeh: Biomechanics of trabecular bone. Annu. Rev. Biomed. Eng. 3, 307-333 (2001).

44. A.C. Deymier-Black, J.D. Pasteris, G.M. Genin, and S. Thomopoulos: Allometry of the tendon enthesis: mechanisms of load transfer between tendon and bone. J. Biomech. Eng. 137, 111005 (2015)

45. K.S. Allan, R.M. Pilliar, J. Wang, M.D. Grynpas, and R.A. Kandel: Formation of biphasic constructs containing cartilage with a calcified zone interface. Tissue Eng. 13, 167-177 (2007).

46. X. Huang, D. Yang, W. Yan, Z. Shi, J. Feng, Y. Gao, W. Weng, and S. Yan: Osteochondral repair using the combination of fibroblast growth factor and amorphous calcium phosphate/poly(l-lactic acid) hybrid materials. Biomaterials 28, 3091-3100 (2007).

47. W. Liu, J. Lipner, J. Xie, C.N. Manning, S. Thomopoulos, and Y. Xia: Nano fiber scaffolds with gradients in mineral content for spatial control of osteogenesis. ACS Appl. Mater. Interfaces 6, 2842-2849 (2014).

48. B.S. Kim, E.J. Kim, J.S. Choi, J.H. Jeong, C.H. Jo, and Y.W. Cho: Human collagen-based multilayer scaffolds for tendon-to-bone interface tissue engineering. J. Biomed. Mater. Res. A 102, 4044-4054 (2014).

49. E. Nyberg, A. Rindone, A. Dorafshar, and W.L. Grayson: Comparison of 3D-printed poly- $\varepsilon$-caprolactone scaffolds functionalized with tricalcium phosphate, hydroxyapatite, bio-oss, or decellularized bone matrix. Tissue Eng. A 23, 503-514 (2017).

50. A. Tevlek, P. Hosseinian, C. Ogutcu, M. Turk, and H.M. Aydin: Bi-layered constructs of poly(glycerol-sebacate)- $\beta$-tricalcium phosphate for bonesoft tissue interface applications. Mater. Sci. Eng. C72, 316-324 (2017).

51. J.P. Spalazzi, S.B. Doty, K.L. Moffat, W.N. Levine, and H.H. Lu: Development of controlled matrix heterogeneity on a triphasic scaffold for orthopedic interface tissue engineering. Tissue Eng. 12, 34973508 (2006)

52. G. Criscenti, A. Longoni, A. Di Luca, C. De Maria, C.A. Van Blitterswijk, G. Vozzi, and L. Moroni: Triphasic scaffolds for the regeneration of the bone-ligament interface. Biofabrication 8, 15009 (2016).

53. J.A. Cooper, H.H. Lu, F.K. Ko, J.W. Freeman, and C.T. Laurencin: Fiber-based tissue-engineered scaffold for ligament replacement: design considerations and in vitro evaluation. Biomaterials 26, 1523-1532 (2005).

54. N.H. Dormer, M. Singh, L. Zhao, N. Mohan, C.J. Berkland, and M.S. Detamore: Osteochondral interface regeneration of the rabbit knee with macroscopic gradients of bioactive signals. J. Biomed. Mater. Res. 100, 162-170 (2012)

55. Y. Liu, S. Thomopoulos, C. Chen, V. Birman, M.J. Buehler, and G.M. Genin: Modelling the mechanics of partially mineralized collagen fibrils, fibres and tissue. J. R. Soc. Interface 11, 20130835 (2014).

56. J.Z. Paxton, K. Donnelly, R.P. Keatch, and K. Baar: Engineering the bone-ligament Interface using polyethylene glycol diacrylate incorporated with hydroxyapatite. Tissue Eng. A 15, 1201-1209 (2009).

57. G.H. Altman, R.L. Horan, H.H. Lu, J. Moreau, I. Martin, J.C. Richmond, and D.L. Kaplan: Silk matrix for tissue engineered anterior cruciate ligaments. Biomaterials 23, 4131-4141 (2002).

58. S. Font Tellado, W. Bonani, E. Rosado Balmayor, P. Föhr, A. Motta, C. Migliaresi, and M. van Griensven: Fabrication and characterization 
of biphasic silk fibroin scaffolds for tendon/ligament-to-bone tissue engineering. Tissue Eng. A 23, 859-872 (2017).

59. Y-B. Park, C-W. Ha, C-H. Lee, and Y-G. Park: Restoration of a large osteochondral defect of the knee using a composite of umbilical cord blood-derived mesenchymal stem cells and hyaluronic acid hydrogel: a case report with a 5-year follow-up. BMC Musculoskelet. Disord. 18, 59 (2017).

60. M.C. McCorry, M.M. Mansfield, X. Sha, D.J. Coppola, J.W. Lee, and L.J. Bonassar: A model system for developing a tissue engineered meniscal enthesis. Acta Biomater. 56, 110-117 (2016).

61. C.H. Chang, F.H. Lin, C.C. Lin, C.H. Chou, and H.C. Liu: Cartilage tissue engineering on the surface of a novel gelatin-calcium- phosphate biphasic scaffold in a double-chamber bioreactor. J. Biomed. Mater. Res.B, Appl. Biomater. 71, 313-321 (2004).

62. I-N.E. Wang, J. Shan, R. Choi, S. Oh, C.K. Kepler, F.H. Chen, and H.H. Lu: Role of osteoblast-fibroblast interactions in the formation of the ligament-to-bone interface. J. Orthop. Res. 25, 1609-1620 (2007).

63. K. Xu, L.A. Kuntz, P. Foehr, K. Kuempel, A. Wagner, J. Tuebel, C.V. Deimling, and R.H. Burgkart: Efficient decellularization for tissue engineering of the tendon-bone interface with preservation of biomechanics. PLOS ONE. 12, e0171577 (2017).

64. S. Sundar, C.J. Pendegrass, and G.W. Blunn: Tendon bone healing can be enhanced by demineralized bone matrix: a functional and histological study. J. Biomed. Mater. Res. B, Appl. Biomater. 88, 115-122 (2009).

65. J. Lipner, H. Shen, L. Cavinatto, W. Liu, N. Havlioglu, Y. Xia, L.M. Galatz, and S. Thomopoulos: In vivo evaluation of adipose-derived stromal cells delivered with a nanofiber scaffold for tendon-to-bone repair. Tissue Eng. A 21, 2766-2774 (2015).

66. U.G. Wegst, H. Bai, E. Saiz, A.P. Tomsia, and R.0. Ritchie: Bioinspired structural materials. Nat. Mater. 14, 23-36 (2014).

67. X. Ding, M. Zhu, B. Xu, J. Zhang, Y. Zhao, S. Ji, L. Wang, L. Wang, X. Li, D. Kong, X. Ma, and Q. Yang: Integrated trilayered silk fibroin scaffold for osteochondral differentiation of adipose-derived stem cells. ACS Appl. Mater. Interfaces 6, 16696-16705 (2014).

68. J. Ma, M.J. Smietana, T.Y. Kostrominova, E.M. Wojtys, L.M. Larkin, and E.M. Arruda: Three-dimensional engineered bone-ligament-bone constructs for anterior cruciate ligament replacement. Tissue Eng. A 18, 103-116 (2012).

69. H.K. Min, S.H. Oh, J.M. Lee, G.I. Im, and J.H. Lee: Porous membrane with reverse gradients of PDGF-BB and BMP-2 for tendon-to-bone repair: In vitro evaluation on adipose-derived stem cell differentiation. Acta Biomater. 10, 1272-1279 (2014).

70. B.M. Baker and R.L. Mauck: The effect of nanofiber alignment on the maturation of engineered meniscus constructs. Biomaterials 28, 1967-1977 (2007).

71. J.S. Park, H.J. Yang, D.G. Woo, H.N. Yang, K. Na, and K.H. Park: Chondrogenic differentiation of mesenchymal stem cells embedded in a scaffold by long-term release of TGF-B3 complexed with chondroitin sulfate. J. Biomed. Mater. Res. A 92, 806-816 (2010).

72. W.M. Han, S-J. Heo, T.P. Driscoll, J.F. Delucca, C.M. McLeod, L.J. Smith, R.L. Duncan, R.L. Mauck, and D.M. Elliott: Microstructural heterogeneity directs micromechanics and mechanobiology in native and engineered fibrocartilage. Nat. Mater. 15, 477-484 (2016).

73. J.P. Spalazzi, E. Dagher, S.B. Doty, X.E. Guo, S.A. Rodeo, and H.H. Lu: In vivo evaluation of a multiphased scaffold designed for orthopaedic interface tissue engineering and soft tissue-to-bone integration. J. Biomed. Mater. Res. A 86, 1-12 (2008).

74. J.L. Puetzer, E. Koo, and L.J. Bonassar: Induction of fiber alignment and mechanical anisotropy in tissue engineered menisci with mechanical anchoring. J. Biomech. 48, 1436-1443 (2015).

75. J.B. Lian and G.S. Stein: Concepts of osteoblast growth and differentiation: basis for modulation of bone cell development and tissue formation. Crit. Rev. Oral Biol. Med. 3, 269-305 (1992).

76. E.J. Mackie, Y.A. Ahmed, L. Tatarczuch, K.S. Chen, and M. Mirams: Endochondral ossification: How cartilage is converted into bone in the developing skeleton. Int. J. Biochem. Cell Biol. 40, 46-62 (2008).

77. L.J. Sandell and T. Aigner: Articular cartilage and changes in arthritis. An introduction: Cell biology of osteoarthritis. Arthritis Res. 3, 107-113 (2001).
78. J. Sanchez-Adams and K.A. Athanasiou: The knee meniscus: a complex tissue of diverse cells. Cell. Mol. Bioeng. 2, 332-340 (2009).

79. K. Spanoudes, D. Gaspar, A. Pandit, and D.I. Zeugolis: The biophysical, biochemical, and biological toolbox for tenogenic phenotype maintenance in vitro. Trends Biotechnol. 32, 474-482 (2014).

80. A. Hasegawa, H. Nakahara, M. Kinoshita, H. Asahara, J. Koziol, and M.K. Lotz: Cellular and extracellular matrix changes in anterior cruciate ligaments during human knee aging and osteoarthritis. Arthritis Res. Ther. 15, R29 (2013).

81. C.H. Lee, S.A. Rodeo, L.A. Fortier, C. Lu, C. Erisken, and J.J. Mao: Protein-releasing polymeric scaffolds induce fibrochondrocytic differentiation of endogenous cells for knee meniscus regeneration in sheep. Sci. Transl. Med. 6, 266ra171 (1-11) (2014).

82. F.A. Monibi and J.L. Cook: Tissue-derived extracellular matrix bioscaffolds: emerging applications in cartilage and meniscus repair. Tissue Eng. B, Rev. 23, 386-398 (2017).

83. E. Zelzer, E. Blitz, M.L. Killian, and S. Thomopoulos: Tendon-to-bone attachment: from development to maturity. Birth Defects Res. Part C. 102, 101-112 (2014).

84. J. Jiang, S.B. Nicoll, and H.H. Lu: Co-culture of osteoblasts and chondrocytes modulates cellular differentiation in vitro. Biochem. Biophys. Res. Commun. 338, 762-770 (2005).

85. M.C. McCorry, J.L. Puetzer, and L.J. Bonassar: Characterization of mesenchymal stem cells and fibrochondrocytes in three-dimensional co-culture: analysis of cell shape, matrix production, and mechanical performance. Stem Cell Res. Ther. 7, 39 (2016).

86. M.C. McCorry and L.J. Bonassar: Fiber development and matrix production in tissue-engineered menisci using bovine mesenchymal stem cells and fibrochondrocytes. Connect. Tissue Res. 58, 329-341 (2017).

87. G. Im: Coculture in musculoskeletal tissue regeneration. Tissue Eng. B, Rev. 20, 545-554 (2014).

88. L. Bian, D.Y. Zhai, R.L. Mauck, and J.A. Burdick: Coculture of human mesenchymal stem cells and enhances functional properties of engineered cartilage reverse primer. Tissue Eng. A 17, 1137-1145 (2011).

89. G.M. Hoben, V.P. Willard, and K.A. Athanasiou: Fibrochondrogenesis of hESCs: growth factor combinations and cocultures. Stem Cells Dev. 18, 283-292 (2009).

90. E. Gardner and R. O'Rahilly: The early development of the knee joint in staged human embryos. J. Anat. 102, 289-299 (1968).

91. D.J. Gray and E. Gardner: Prenatal development of the human knee and superior tibiofibular joints. Am. J. Anat. 86, 235-287 (1950).

92. J.A. Mérida-Velasco, I. Sánchez-Montesinos, J. Espín-Ferra, J.F. Rodríguez-Vázquez, J.R. Mérida-Velasco, and J. Jiménez-Collado: Development of the human knee joint. Anat. Rec. 248, 269-278 (1997).

93. A.I. Caplan and J.E. Dennis: Mesenchymal stem cells as trophic mediators. J. Cell. Biochem. 98, 1076-1084 (2006).

94. A.M. Mackay, S.C. Beck, J.M. Murphy, F.P. Barry, C.O. Chichester, and M.F. Pittenger: Chondrogenic differentiation of cultured human mesenchymal stem cells from marrow. Tissue Eng. 4, 415-428 (1998).

95. G.I. Im, Y.W. Shin, and K.B. Lee: Do adipose tissue-derived mesenchymal stem cells have the same osteogenic and chondrogenic potential as bone marrow-derived cells? Osteoarthr. Cartil. 13, 845-853 (2005).

96. J.P. Spalazzi and H.H. Lu: Osteoblast and chondrocyte interactions during coculture on scaffolds. IEEE Eng. Med. Biol. Mag. 22, 27-34 (2003).

97. N.J. Gunja and K.A. Athanasiou: Passage and reversal effects on gene expression of bovine meniscal fibrochondrocytes. Arthritis Res. Ther. 9, 1-12 (2007).

98. C. Zeltz and D. Gullberg: The integrin-collagen connection-a glue for tissue repair? J. Cell Sci. 129, 653-664 (2016).

99. A.D. Augst, H.J. Kong, and D.J. Mooney: Alginate hydrogels as biomaterials. Macromol. Biosci. 6, 623-633 (2006).

100.B.M. Baker, A.S. Nathan, A.O. Gee, R.L. Mauck: The influence of an aligned nanofibrous topography on human mesenchymal stem cell fibrochondrogenesis. Biomaterials 31, 6190-6200 (2010).

101.J.R. Tse, and A.J. Engler: Stiffness gradients mimicking in vivo tissue variation regulate mesenchymal stem cell fate. PLOS ONE 6, e15978 (2011).

102.A.J. Engler, S. Sen, H.L. Sweeney, and D.E. Discher: Matrix elasticity directs stem cell lineage specification. Cell 126, 677-689 (2006). 
103.C.H. Lee, H.J. Shin, I.H. Cho, Y-M. Kang, I.A. Kim, K-D. Park, and J-W. Shin: Nanofiber alignment and direction of mechanical strain affect the ECM production of human ACL fibroblast. Biomaterials 26, 12611270 (2005).

104.S.D. Subramony, B.R. Dargis, M. Castillo, E.U. Azeloglu, M.S. Tracey, A. Su, and H.H. Lu: The guidance of stem cell differentiation by substrate alignment and mechanical stimulation. Biomaterials 34, 1942-1953 (2013).

105.J.E. Phillips, K.L. Burns, J.M. Le Doux, R.E. Guldberg, and A.J. García: Engineering graded tissue interfaces. Proc. Natl. Acad. Sci. USA 105, 12170-12175 (2008).

106.M. Urist, R. DeLange, and G. Finerman: Bone cell differentiation and growth factors. Science 220, 680-686 (1983).

107.T.A. Linkhart, S. Mohan, and D.J. Baylink: Growth factors for bone growth and repair: IGF, TGF and BMP. Bone 19, 1S-12S (1996).

108.J.R. Lieberman, A. Daluiski, and T.A. Einhorn: The Role of growth factors in the repair of bone. J. Bone oin Surg. 84, 1032-1044 (2002).

109.T. Molloy, Y. Wang, and G.A.C. Murrell: The roles of growth factors in tendon and ligament healing. Sport. Med. 33, 381-394 (2003).

110.R. James, G. Kesturu, G. Balian, and A.B. Chhabra: Tendon: biology, biomechanics, repair, growth factors, and evolving treatment options. J. Hand Surg. Am. 33, 102-112 (2008).

111.P.M. Van der Kraan, P. Buma, T. Van Kuppevelt, and W.B. Van Den Berg: Interaction of chondrocytes, extracellular matrix and growth factors: relevance for articular cartilage tissue engineering. Osteoarthr. Cartil. 10, 631-637 (2002)

112.D.J. Baylink, R.D. Finkelman, and S. Mohan: Growth factors to stimulate bone formation. J. Bone Miner. Res. 8, S565-S572 (1993).

113.C. Li, C. Vepari, H-J. Jin, H.J. Kim, and D.L. Kaplan: Electrospun silk-BMP-2 scaffolds for bone tissue engineering. Biomaterials 27, 3115-3124 (2006).

114.N. Kakudo, K. Kusumoto, Y.B. Wang, Y. Iguchi, and Y. Ogawa: Immunolocalization of vascular endothelial growth factor on intramuscular ectopic osteoinduction by bone morphogenetic protein-2. Life Sci. 79, 1847-1855 (2006).

115.Z.S. Patel, S. Young, Y. Tabata, J.A. Jansen, M.E.K. Wong, and A. G. Mikos: Dual delivery of an angiogenic and an osteogenic growth factor for bone regeneration in a critical size defect model. Bone 43, 931-940 (2008).

116.J.A. Parry, M.G.L. Olthof, K.L. Shogren, M. Dadsetan, A. Van Wijnen, M. Yaszemski, and S. Kakar: Three-dimension-printed porous poly(propylene fumarate) scaffolds with delayed rhBMP-2 release for anterior cruciate ligament graft fixation. Tissue Eng. A 0, 1-7 (2017).

117.N. Indrawattana, G. Chen, M. Tadokoro, L.H. Shann, H. Ohgushi, T. Tateishi, J. Tanaka, and A. Bunyaratvej: Growth factor combination for chondrogenic induction from human mesenchymal stem cell. Biochem. Biophys. Res. Commun. 320, 914-919 (2004).

118.P. Yilgor, K. Tuzlakoglu, R.L. Reis, N. Hasirci, and V. Hasirci: Incorporation of a sequential BMP-2/BMP-7 delivery system into chitosan-based scaffolds for bone tissue engineering. Biomaterials $\mathbf{3 0}$, 3551-3559 (2009).

119.J.T. Connelly, C.G. Wilson, and M.E. Levenston: Characterization of proteoglycan production and processing by chondrocytes and BMSCs in tissue engineered constructs. Osteoarthr. Cartil. 16, 1092-1100 (2008).

120. B. Johnstone, T.M. Hering, A.I. Caplan, V.M. Goldberg, and J.U. Yoo: In vitro chondrogenesis of bone marrow-derived mesenchymal progenitor cells. Exp. Cell Res. 238, 265-272 (1998).

121.R.F. Macbarb, E.A. Makris, J.C. Hu, and K.A. Athanasiou: A chondroitinase-ABC and TGF- $\beta 1$ treatment regimen for enhancing the mechanical properties of tissue-engineered fibrocartilage. Acta Biomater. 9, 4626-4634 (2012)

122. R.P. Marini, I. Martin, M.M. Stevens, R. Langer, and V.P. Shastri: FGF-2 enhances TGF-B1 induced periosteal chondrogenesis. J. Orthop. Res. 22, 1114-1119 (2004).

123.S.M. Imler, A.N. Doshi, and M.E. Levenston: Combined effects of growth factors and static mechanical compression on meniscus explant biosynthesis. Osteoarthr. Cartil. 12, 736-744 (2004).

124.A. Augst, D. Marolt, L.E. Freed, C. Vepari, L. Meinel, M. Farley, R. Fajardo, N. Patel, M. Gray, D.L. Kaplan, and G. Vunjak-Novakovic:
Effects of chondrogenic and osteogenic regulatory factors on composite constructs grown using human mesenchymal stem cells, silk scaffolds and bioreactors. J. R. Soc. Interface 5, 929-939 (2008).

125. H. Park, J.S. Temenoff, T.A. Holland, Y. Tabata, and A.G. Mikos: Delivery of TGF-1 and chondrocytes via injectable, biodegradable hydrogels for cartilage tissue engineering applications. Biomaterials 26, 7095-7103 (2005).

126. M.B. Mueller, M. Fischer, J. Zellner, A. Berner, T. Dienstknecht, L. Prantl, R. Kujat, M. Nerlich, R.S. Tuan, and P. Angele: Hypertrophy in mesenchymal stem cell chondrogenesis: effect of TGF- $\beta$ isoforms and chondrogenic conditioning. Cells Tissues Organs 192, 158-166 (2010).

127.M. Kim, I.E. Erickson, M. Choudhury, N. Pleshko, and R.L. Mauck: Transient exposure to TGF-B3 improves the functional chondrogenesis of MSC-laden hyaluronic acid hydrogels. J. Mech. Behav. Biomed. Mater. 11, 92-101 (2012).

128.E. Farng, A.R.U. Bs, D.B. Bs, S.E. Bs, and D.R. Mcallister: The effects of GDF-5 and uniaxial strain on mesenchymal stem cells in 3-D culture. Clin. Orthop. Relat. Res. 466, 1930-1937 (2008).

129.R. James, S.G. Kumbar, C.T. Laurencin, G. Balian, and A.B. Chhabra: Tendon tissue engineering : adipose-derived stem cell and GDF-5 mediated regeneration using electrospun matrix systems. Biomed. Mater. 6, 25011 (2011).

130.N.I. Aguilar, S. Trippel, S. Shi, and L.J. Bonassar: Customized biomaterials to augment chondrocyte gene therapy. Acta Biomater. 53, 260-267 (2017)

131.J.L. Puetzer, B.N. Brown, J.J. Ballyns, and L.J. Bonassar: The effect of IGF-I on anatomically shaped tissue-engineered menisci. Tissue Eng. A 19, 1443-1450 (2013).

132.S. Thomopoulos, F.L. Harwood, M.J. Silva, D. Amiel, and R.H. Gelberman: Effect of several growth factors on canine flexor tendon fibroblast proliferation and collagen synthesis in vitro. J. Hand Surg. Am. 30, 441-447 (2005).

133.C.K. Hee, J.S. Dines, L.A. Solchaga, V.R. Shah, and J.O. Hollinger: Regenerative tendon and ligament healing: opportunities with recombinant human platelet-derived growth factor BB-homodimer. Tissue Eng. B, Rev. 18, 225-234 (2012).

134.B.S. Yoon, R. Pogue, D.A. Ovchinnikov, I. Yoshii, Y. Mishina, R.R. Behringer, and K.M. Lyons: BMPs regulate multiple aspects of growthplate chondrogenesis through opposing actions on FGF pathways. Development 133, 4667-4678 (2006).

135.E. Minina, C. Kreschel, M.C. Naski, D.M. Ornitz, and A. Vortkamp: Interaction of FGF, Ihh/Pthlh, and BMP signaling integrates chondrocyte proliferation and hypertrophic differentiation. Dev. Cell 3, 439-449 (2002).

136.P.C. Bessa, M. Casal, and R.L. Reis: Bone morphogenetic proteins in tissue engineering: the road from laboratory to clinic, part II (BMP delivery). J. Tissue Eng. Regen. Med. 2, 81-96 (2008).

137.N.M. Wolfman, G. Hattersley, K. Cox, A.J. Celeste, R. Nelson, N. Yamaji, J.L. Dube, E. Diblasio-smith, J. Nove, J.J. Song, J.M. Wozney, V. Rosen, N.M. Wolfman, G. Hattersley, K. Cox, and J. Anthony: Ectopic induction of tendon and ligament in rats by growth and differentiation factors 5,6 , and 7, members of the TGF- $\beta$ gene family. J. Clin. Invest. 100, 321-330 (1997).

138.D. Chen, M. Zhao, G.R. Mundy, D. Chen, M. Zhao, G.R. Mundy, and B. Morphogenetic: Bone morphogenetic proteins. Growth Factors 22, 233-241 (2004)

139.R.S. Decker, H-B. Um, N.A. Dyment, N. Cottingham, Y. Usami, M. Enomoto-Iwamoto, M.S. Kronenberg, P. Maye, D.W. Rowe, E. Koyama, and M. Pacifici: Cell origin, volume and arrangement are drivers of articular cartilage formation, morphogenesis and response to injury in mouse limbs. Dev. Biol. 426, 56-68 (2017).

140.U. Heine, E.F. Munoz, K.C. Flanders, L.R. Ellingsworth, H.Y. Lam, N.L. Thompson, A.B. Roberts, and M.B. Sporn: Role of transforming growth factor-beta in the development of the mouse embryo. J. Cell Biol. 105, 2861-2876 (1987).

141.C.M. Leonard, H.M. Fuld, D.A. Frenz, S.A. Downie, J. Massague, and S.A. Newman: Role of transforming growth factor-B in chondrogenic pattern formation in the embryonic limb: stimulation of mesenchymal condensation and fibronectin gene expression by exogenous TGF-B and evidence for endogenous TGF-B-like activity. Dev. Biol. 145, 99-109 (1991). 
142.W.M. Kulyk, B.J. Rodgers, K. Greer, and R.A. Kosher: Promotion of embryonic chick limb cartilage differentiation by transforming growth factor-B. Dev. Biol. 135, 424-430 (1989).

143.0.G.P. Isaksson, J-0. Jansson, and I.A.M. Gause: Growth hormone stimulates longitudinal bone growth. Science 216, 1237-1239 (1982).

144.S. Mohan, Y. Nakao, Y. Honda, E. Landale, U. Leser, C. Dony, K. Lang, and D.J. Baylink: Studies on the mechanisms by which insulin-like growth factor (IGF) binding protein-4 (IGFBP-4) and IGFBP-5 modulate IGF actions in bone cells. J. Biol. Chem. 270, 20424-20431 (1995).

145.E.B. Hunziker, J. Wagner, and J. Zapf: Differential effects of insulin-like growth factor I and growth hormone on developmental stages of rat growth plate chondrocytes in vivo. J. Clin. Invest. 93, 1078-1086 (1994).

146.S.O. Abrahamsson: Similar effects of recombinant human insulin-like growth factor-I and II on cellular activities in flexor tendons of young rabbits: Experimental studies in vitro. J. Orthop. Res. 15, 256-262 (1997).

147.V. Midy and J. Plouët: Vasculotropin/vascular endothelial growth factor induces differentiation in cultured osteoblasts. Biochem. Biophys. Res. Commun. 199, 380-386 (1994).

148.D.W. Leung, G. Cachianes, W.J. Kuang, D.V. Goeddel, and N. Ferrara: Vascular endothelial growth factor is a secreted angiogenic mitogen. Science 246, 1306-1309 (1989).

149.P.J. Keck, S.D. Hauser, G. Krivi, K. Sanzo, T. Warren, J. Feder, and D.T. Connolly: Vascular permeability factor, an endothelial cell mitogen related to PDGF. Science 246, 1309-1312 (1989).

150.S.K.C. Sundararaj, R.D. Cieply, G. Gupta, T.A. Milbrandt, and D.A. Puleo: Treatment of growth plate injury using IGF-1 loaded PLGA scaffold. J. Tissue Eng. Regen. Med. 9, E202-E209 (2015).

151.K.J. Gooch, T. Blunk, D.L. Courter, A.L. Sieminski, P.M. Bursac, G. Vunjak-Novakovic, and L.E. Freed: IGF-I and mechanical environment interact to modulate engineered cartilage development. Biochem. Biophys. Res. Commun. 286, 909-915 (2001).

152.W.L. Murphy, M.C. Peters, D.H. Kohn, and D.J. Mooney: Sustained release of vascular endothelial growth factor from mineralized poly (lactide-co-glycolide) scaffolds for tissue engineering. Biomaterials 21, 2521-2527 (2000).

153.A.F. Steinert, G.D. Palmer, R. Capito, J.G. Hofstaetter, C. Pilapil, S.C. Ghivizzani, M. Spector, and C.H. Evans: Genetically enhanced engineering of meniscus tissue using ex vivo delivery of transforming growth factor-beta 1 complementary deoxyribonucleic acid. Tissue Eng. 13, 2227-2237 (2007).

154.H.V. Almeida, Y. Liu, G.M. Cunniffe, K.J. Mulhall, A. Matsiko, C.T. Buckley, F.J. O'Brien, and D.J. Kelly: Controlled release of transforming growth factor- $\beta 3$ from cartilage-extra-cellular-matrix-derived scaffolds to promote chondrogenesis of human-joint-tissue-derived stem cells. Acta Biomater. 10, 4400-4409 (2014).

155.A. Hildebrand, M. Romarís, L.M. Rasmussen, D. Heinegård, D.R. Twardzik, W.A. Border, and E. Ruoslahti: Interaction of the small interstitial proteoglycans biglycan, decorin and fibromodulin with transforming growth factor beta. Biochem. J. 302, 527-534 (1994).

156.W-N. Qi and S.P. Scully: Extracellular collagen regulates expression of trasforming growth factor-beta1 gene. J. Orthop. Res. 18, 928-932 (2000).

157.M. Mongiat, J. Otto, R. Oldershaw, F. Ferrer, J.D. Sato, and R.V. Iozzo: Fibroblast growth factor-binding protein is a novel partner for perlecan protein core. J. Biol. Chem. 276, 10263-10271 (2001).

158. R. Ruppert, E. Hoffmann, and W. Sebald: Human bone morphogenetic protein 2 contains a heparin-binding site which modifies its biological activity. Eur. J. Biochem. 237, 295-302 (1996).

159.Y. Zhu, A. Oganesian, D.R. Keene, and L.J. Sandell: Type IIA procollagen containing the cysteine-rich amino propeptide is deposited in the extracellular matrix of prechondrogenic tissue and binds to TGF-B1 and BMP-2. J. Cell Biol. 144, 1069-1080 (1999).

160.M. Kawecki, W. Łabuś, A. Klama-Baryla, D. Kitala, M. Kraut, J. Glik, M. Misiuga, M. Nowak, T. Bielecki, and A. Kasperczyk: A review of decellurization methods caused by an urgent need for quality control of cellfree extracellular matrix' scaffolds and their role in regenerative medicine. J. Biomed. Mater. Res. Part B Appl. Biomater. 1-15 (2017). doi: 10.1002/jbm.b.33865.

161.S. Farnebo, C.Y. Woon, M. Kim, H. Pham, and J. Chang: Reconstruction of the tendon-bone insertion with decellularized tendon-bone composite grafts: comparison with onventional repair. J. Hand Surg. Am. 39, 6574 (2014).

162.A.G. Schwartz, J.H. Lipner, J.D. Pasteris, G.M. Genin, and $S$. Thomopoulos: Muscle loading is necessary for the formation of a functional tendon enthesis. Bone 55, 44-51 (2013).

163.H. Lin, T.P. Lozito, P.G. Alexander, R. Gottardi, and R.S. Tuan: Stem cell-based microphysiological osteochondral system to model tissue response to interleukin-1 $\beta$. Mol. Pharm. 11, 2203-2212 (2014).

164.W.L. Grayson, S. Bhumiratana, P.H. Grace Chao, C.T. Hung, and G. Vunjak-Novakovic: Spatial regulation of human mesenchymal stem cell differentiation in engineered osteochondral constructs: effects of pre-differentiation, soluble factors and medium perfusion. Osteoarthr. Cartil. 18, 714-723 (2010).

165.S.M. Goldman and G.A. Barabino: Spatial Engineering of osteochondral tissue constructs through microfluidically directed differentiation of mesenchymal stem cells. Biores. Open Access 5.1, 109-117 (2016).

166.N. Jaiswal, S.E. Haynesworth, A.I. Caplan, and S.P. Bruder: Osteogenic differentiation of purified, culture-expanded human mesenchymal stem cells in vitro. J. Cell. Biochem. 64, 295-312 (1997).

167.W.L. Grayson, M. Fröhlich, K. Yeager, S. Bhumiratana, M.E. Chan, C. Cannizzaro, L.Q. Wan, X.S. Liu, X.E. Guo, and G. Vunjak-Novakovic: Engineering anatomically shaped human bone grafts. Proc. Natl. Acad. Sci. USA 107, 3299-3304 (2010).

168.A.L. Boskey and R. Roy: Cell culture systems for studies of bone and tooth mineralization. Chem. Rev. 108, 4716-4733 (2008).

169. R-I. Hata and H. Senoo: L-Ascorbic acid 2-phosphate stimulates collagen accumulation, cell proliferation, and formation of a threedimensional tissue like substance by skin fibroblasts. J. Cell. Physiol. 138, 8-16 (1989)

170.R.I. Schwarz, P. Kleinman, and N. Owens: Ascorbate can act as an inducer of the collagen pathway because most steps are tightly coupled. Ann. New York Acad. Sci. 498, 172-185 (1987).

171.Q. Li, F. Qu, B. Han, R. Mauck, L. Han, and D. Ph: Micromechanical heterogeneity and anisotropy of the meniscus extracellular matrix. Acta Biomater. 54, 356-366 (2017).

172.S.M. Goldman and G.A. Barabino: Cultivation of agarose-based microfluidic hydrogel promotes the development of large, full-thickness, tissue-engineered articular cartilage constructs. J. Tissue Eng. Regen. Med. 11, 572-581 (2014).

173.S. Thomopoulos, J.P. Marquez, B. Weinberger, V. Birman, and G.M. Genin: Collagen fiber orientation at the tendon to bone insertion and its influence on stress concentrations. J. Biomech. 39, 1842-1851 (2006).

174.D.F. Villegas, T.A. Hansen, D.F. Liu, and T.L. Haut Donahue: A quantitative study of the microstructure and biochemistry of the medial meniscal horn attachments. Ann. Biomed. Eng. 36, 123-131 (2008).

175.D.F. Villegas, and T.L. Haut Donahue: Collagen morphology in human meniscal attachments: a SEM study. Connect. Tissue Res. 51, 327$336(2010)$

176.D.F. Villegas, J.A. Maes, S.D. Magee, and T.L. Haut Donahue: Failure properties and strain distribution analysis of meniscal attachments. J. Biomech. 40, 2655-2662 (2007).

177.Y. Hu, V. Birman, A. Demyier-Black, A.G. Schwartz, S. Thomopoulos, and G.M. Genin: Stochastic interdigitation as a toughening mechanism at the interface between tendon and bone. Biophys. J. 108, 431-437 (2015).

178.H.M. Kim, L.M. Galatz, N. Patel, R. Das, and S. Thomopoulos: Recovery potential after postnatal shoulder paralysis. J. Bone Jt. Surg. 91, 879891 (2009).

179.S. Thomopoulos, G.R. Williams, and L.J. Soslowsky: Tendon to bone healing: differences in biomechanical, structural, and compositional properties due to a range of activity levels. J. Biomech. Eng. 125, 106 (2003).

180.C.R. Clark and J.A. Ogden: Prenatal and postnatal development of human knee joint mensci. lowa Orthop. J. 1, 20-27 (1981). 
181.D. Huang, T.R. Chang, A. Aggarwal, R.C. Lee, H.P. Ehrlich: Mechanisms and dynamics of mechanical strengthening in ligament-equivalent fibroblast-populated collagen matrices. Ann. Biomed. Eng. 21, 289305 (1993).

182.S. Thomopoulos, G.M. Fomovsky, and J.W. Holmes: The development of structural and mechanical anisotropy in fibroblast populated collagen gels. J. Biomech. Eng. 127, 742-750 (2005).

183.F. Grinnell: Fibroblast-collagen-matrix contraction: growth-factor signalling and mechanical loading. Trends Cell Biol. 10, 362-365 (2000).

184.K.D. Costa, E.J. Lee, and J.W. Holmes: Creating alignment and anisotropy in engineered heart tissue: role of boundary conditions in a model three-dimensional culture system. Tissue Eng. 9, 567-577 (2003).

185. V.S. Nirmalanandhan, M.S. Levy, A.J. Huth, and D.L. Butler: Effects of cell seeding density and collagen concentration on contraction kinetics of mesenchymal stem cell-seeded collagen constructs. Tissue Eng. 12, 1865-1872 (2006).

186.R.G. Young, D.L. Butler, W. Weber, A.I. Caplan, S.L. Gordon, and D.J. Fink: Use of mesenchymal stem cells in a collagen matrix for Achilles tendon repair. J. Orthop. Res. 16, 406-413 (1998).

187.H.A. Awad, D.L. Butler, M.T. Harris, R.E. Ibrahim, Y. Wu, R.G. Young, S. Kadiyala, G.P. Boivin: In vitro characterization of mesenchymal stem cell-seeded collagen scaffolds for tendon repair: effects of initial seeding density on contraction kinetics. J. Biomed. Mater. Res. 51, 233-240 (2000).

188.R.D. Bowles, R.M. Williams, W.R. Zipfel, and L.J. Bonassar: Selfassembly of aligned tissue-engineered annulus fibrosus and intervertebral disc composite via collagen gel contraction. Tissue Eng. Part A 16, 1339-1348 (2010).

189.J.L. Puetzer, I. Sallent, A. Gelmi, and M.M. Stevens: Investigating collagen fiber formation for functional musculoskeletal engineering: going beyond the fibril. ORS 2017 Annual Meeting, San Diego, CA, Session No. 50, Vol. 42, Paper No. 348, 2017.

190.D.J. Huey and K.A. Athanasiou: Tension-compression loading with chemical stimulation results in additive increases to functional properties of anatomic meniscal constructs. PLOS ONE 6, e27857 (2011).

191.J.L. Puetzer and L.J. Bonassar: Physiologically distributed loading patterns drive the formation of zonally organized collagen structures in tissue engineered meniscus. Tissue Eng. A 22, 907-916 (2016).

192.C.T. Hendley, J. Tao, J.A. Kunitake, J.J. De Yoreo, and L.A. Estroff: Microscopy techniques for investigating the control of organic constituents on biomineralization. MRS Bull. 40, 480-489 (2015)

193.H. Wang, A.O. Gee, I.D. Hutchinson, K. Stoner, R.F. Warren, T.O. Chen and S.A. Maher: Bone plug versus suture-only fixation of meniscal grafts: effect on joint contact mechanics during simulated gait. Am. J. Sports Med. 42, 1682-1689 (2014).

194.K.A. Ross, R.M. Williams, L.V. Schnabel, H.O. Mohammed, H.G. Potter, G. Bradica, E. Castiglione, S.L. Pownder, P.W. Satchell, R.A. Saska, and L.A. Fortier: Comparison of three methods to quantify repair cartilage collagen orientation. Cartilage 4, 111-120 (2013).

195.N.T. Khanarian, M.K. Boushell, J.P. Spalazzi, N. Pleshko, A.L. Boskey, and H.H. Lu: FTIR-I compositional mapping of the cartilage-to-bone interface as a function of tissue region and age. J. Bone Miner. Res. 29, 1-26 (2014).

196.J.C. Mansfield, J. Moger, E. Green, C. Moger, and C.P. Winlove: Chemically specific imaging and in-situ chemical analysis of articular cartilage with stimulated Raman scattering. J. Biophotonics 6, 803814 (2013).

197.S. Yamanaka: A fresh look at iPS cells. Cell 137, 13-17 (2009).

198.E.S. Lander: The heroes of CRISPR. Cell 164, 18-28 (2016).

199.N.W. Choi, M. Cabodi, B. Held, J.P. Gleghorn, L.J. Bonassar, and A. D. Stroock: Microfluidic scaffolds for tissue engineering. Nat. Mater. 6, 908-915 (2007).

200.R.R. Jose, M.J. Rodriguez, T.A. Dixon, F. Omenetto, and D.L. Kaplan: Evolution of bioinks and additive manufacturing technologies for 3D bioprinting. ACS Biomater. Sci. Eng. 2, 1662-1678 (2016). 